OPEN ACCESS

Edited by:

Zvy Dubinsky,

Bar-Ilan University, Israel

Reviewed by:

Itay Cohen,

Hebrew University of Jerusalem, Israel

Stephane Roberty,

University of Liège, Belgium

${ }^{*}$ Correspondence:

Matthew R. Nitschke

matthew.nitschke@uts.edu.au

Specialty section: This article was submitted to

Coral Reef Research,

a section of the journal

Frontiers in Marine Science

Received: 20 April 2017 Accepted: 31 January 2018 Published: 14 February 2018

Citation:

Nitschke MR, Gardner SG, Goyen S,

Fujise L, Camp EF, Ralph PJ and

Suggett DJ (2018) Utility of

Photochemical Traits as Diagnostics of Thermal Tolerance amongst Great

Barrier Reef Corals.

Front. Mar. Sci. 5:45.

doi: 10.3389/fmars.2018.00045

\section{Utility of Photochemical Traits as Diagnostics of Thermal Tolerance amongst Great Barrier Reef Corals}

\author{
Matthew R. Nitschke ${ }^{1,2 \star}$, Stephanie G. Gardner ${ }^{1}$, Samantha Goyen ${ }^{1}$, Lisa Fujise ${ }^{1}$, \\ Emma F. Camp ${ }^{1}$, Peter J. Ralph ${ }^{1}$ and David J. Suggett ${ }^{1}$ \\ ${ }^{1}$ Climate Change Cluster (C3), University of Technology Sydney, Sydney, NSW, Australia, ${ }^{2}$ Centre for Environmental and \\ Marine Studies, University of Aveiro, Aveiro, Portugal
}

Light availability is considered a key factor regulating the thermal sensitivity of reef building corals, where excessive excitation of photosystem II (PSII) further exacerbates pressure on photochemical pathways already compromised by heat stress. Coral symbionts acclimate to changes in light availability (photoacclimation) by continually fine-tuning the photochemical operating efficiency of PSII. However, how this process adjusts throughout the warmest months in naturally heat-tolerant or sensitive species is unknown, and whether this influences the capacity to tolerate transient heat stress is untested. We therefore examined the PSIl photophysiology of 10 coral species (with known thermal tolerances) from shallow reef environments at Heron Island (Great Barrier Reef, Australia), in spring (October-November, 2015) vs. summer (February-March, 2016). Corals were maintained in flow-through aquaria and rapid light curve (RLC) protocols using pulse amplitude modulated (PAM) fluorometry captured changes in the PSII photoacclimation strategy, characterized as the minimum saturating irradiance $\left(E_{k}\right)$, and the extent of photochemical ([1 $-C]$, operating efficiency) vs. non-photochemical ([1-Q]) energy dissipation. Values of $E_{k}$ across species were $>2$-fold higher in all coral species in spring, consistent with a climate of higher overall light exposure (i.e., higher PAR from lower cloud cover, rainfall and wind speed) compared with summer. Summer decreases in $E_{k}$ were combined with a shift toward preferential photochemical quenching in all species. All coral species were subsequently subjected to thermal stress assays. An equivalent temperature-ramping profile of $1^{\circ} \mathrm{C}$ increase per day and then maintenance at $32^{\circ} \mathrm{C}$ was applied in each season. Despite the significant seasonal photoacclimation, the species hierarchy of thermal tolerance [maximum quantum yields of PSII $\left(F_{v} / F_{m}\right)$, monitored at dawn and dusk] did not shift between seasons, except for Pocillopora damicornis (faster declines in summer) and Stylophora pistillata (total mortality in spring). Furthermore, the strategy for dealing with light energy (i.e., preferential photochemical vs. non-photochemical quenching) was unchanged for thermally tolerant species across seasons, whereas thermally sensitive species switched between preferential [1-Q] and $[1-C]$ from spring to summer. We discuss how such traits can potentially be used as a diagnostic of thermal tolerance under non-stressed conditions.

Keywords: coral bleaching, Symbiodinium, photoacclimation, photochemical quenching, non-photochemical quenching, thermal tolerance, PSII 


\section{INTRODUCTION}

Photosynthetic dinoflagellates of the genus Symbiodinium are endosymbionts of scleractinian corals that support reef-building, but are highly susceptible to photochemical destabilization when exposed to anomalous environmental conditions (Smith et al., 2005; Roth, 2014; Warner and Suggett, 2016). Under extreme cases, the light harvesting pigments of Symbiodinium are impaired and individual cells are expelled from the host or degraded, which manifests as conspicuous de-colouration referred to as "coral bleaching" (Weis, 2008; Suggett and Smith, 2011). Whilst the term "bleaching" is used interchangeably across scales (i.e., from individual polyps and colonies to reefs) and its process is exacerbated under a number of conditions (from light stress to inorganic nutrient imbalance; Baker et al., 2008; Wiedenmann et al., 2013), widespread "mass bleaching" events are considered a symptom of prolonged anomalous elevated seawater temperatures (Ainsworth et al., 2016) acting synergistically with additional stressors, notably solar radiation (Jones et al., 1998; Mumby et al., 2001; Anthony et al., 2007; Wooldridge et al., 2017). Such conditions led to the single greatest mass bleaching event on the Great Barrier Reef in 2016 (Hughes et al., 2017) and if prolonged, can drive a transition from coral bleaching to coral mortality (Suggett and Smith, 2011).

Whilst anomalous temperatures appear to target numerous physiological pathways of both the coral host and their Symbiodinium populations (Baird et al., 2009; Maor-Landaw and Levy, 2016), functional impairment of Symbiodinium's photosystem II (PSII) reaction centers (RCII) often responds as a primary determinant of bleaching-stress susceptibility (Warner et al., 1999; Takahashi et al., 2008). PSII utilizes absorbed light energy to drive electron generation for energy (ATP) and reductant (NADPH) formation, supporting carbon fixation (Oakley et al., 2014). Excitation pressure on PSII is governed by the rate of electron delivery (photon absorption) vs. removal (i.e., electron flow). Thus, (photo)acclimation via constituents of the light harvesting complex (Robison and Warner, 2006; Hennige et al., 2009) and linear electron transport chain (Robison and Warner, 2006; Suggett et al., 2015) ensure that the redox state of the electron carrier molecules (i.e., plastoquinone) are continually fine-tuned to remain optimal. In shallow reef habitats Symbiodinium cells exist within highly dynamic light

\footnotetext{
Abbreviations: PSII, Photosystem II; $F_{q}{ }^{\prime} / F_{m}{ }^{\prime}$, Effective photochemical efficiency of PSII; RCII, Photosystem II reaction centers; NPQ, Non-photochemical quenching; $[1-Q]$, Light dependant non-photochemical quenching; $[1-C]$, Light dependant photochemical quenching; SST, Sea surface temperature; PAR, Photosynthetically active radiation; E, PAR; RLC, Rapid light curves; F, Darkadapted chlorophyll steady state fluorescence; $F_{o}$, Dark-adapted chlorophyll fluorescence minimum; $F_{m}$, Dark-adapted chlorophyll fluorescence maximum; $F^{\prime}$, Light-adapted chlorophyll steady-state fluorescence under actinic light; $F_{o}{ }^{\prime}$, Light-adapted chlorophyll fluorescence minimum under actinic light; $F_{m}{ }^{\prime}$, Lightadapted chlorophyll fluorescence maximum under actinic light; $F_{v} / F_{m}$, Maximum quantum yield of photosystem II; $F_{q}^{\prime} / F_{m}^{\prime}{ }_{(\max )}$, maximum PSII photochemical efficiency; $E_{k}$, Minimum saturating irradiance of PSII; $E / E_{k}, E_{k}$ normalized to PAR; $S$, Parameter related to the length of the period during which $F_{v} / F_{m}$ remains stable; $k$, Rate constant that quantifies the rate of $F_{v} / F_{m}$ decrease; $F_{v} / F_{m(\min )}$, Minimum dark-acclimated maximum quantum yield of photosystem II reached during exposure to heat stress.
}

fields (Anthony et al., 2004; Roth, 2014) where ambient photon delivery (incident irradiance) to the light harvesting apparatus and subsequent electron turnover often exceeds the capacity to which cells have acclimatized. Therefore, in order to avoid photoinhibition, cells must employ high rates of protein repair (Takahashi et al., 2004; Ragni et al., 2010; Hill et al., 2011; Jeans et al., 2013), or photoprotection mechanisms that transiently redirect excitation energy from linear electron flow via "non-photochemical" quenching pathways. Non-photochemical quenching in Symbiodinium is largely sustained through energydependent quenching via "alternate" electron acceptors within the photochemical electron transport chain (Roberty et al., 2014), as well as alteration of pigment protein transfer efficiencies within the PSII light harvesting antenna complex (McCabe Reynolds et al., 2008; Slavov et al., 2016), to dissipate $>80 \%$ of excitation energy (Gorbunov et al., 2001; Brodersen et al., 2014; Roth, 2014). However, during heat stress, electron transfer through PSII is thought to become increasingly constrained (Tchernov et al., 2004; Smith et al., 2005; Goyen et al., 2017) placing increased reliance on non-photochemical pathways to relieve PSII excitation pressure (Warner et al., 1996; Hill et al., 2004; Roberty et al., 2015). Consequently, light availability can determine the severity with which heat stress manifests (Lesser and Farrell, 2004; Robison and Warner, 2006) resulting in persistent and irreversible PSII photoinhibition of Symbiodinium.

Symbiodinium photoacclimation to changes in light availability (photosynthetically active radiation, PAR) has been particularly well-studied in hospite of corals distributed along natural spatial light gradients (Iglesias-Prieto et al., 2004), and shallow to mesophotic (Frade et al., 2008; Lesser et al., 2010; Cooper et al., 2011) and clear to turbid (Hennige et al., 2008; Suggett et al., 2012) waters, complimented with reciprocal transplants of coral species across these habitats (Cohen and Dubinsky, 2015). Here, upon moving Symbiodinium to darker or deeper habitats, light-harvesting efficiency is altered through adjustment of light-harvesting capacity (Frade et al., 2008). This process likely reflects interactions between the macrostructure of the host (i.e., lateral transfer or local enhancement of light through tissue layers and skeleton; Enríquez et al., 2005, 2017; Terán et al., 2010; Wangpraseurt et al., 2012) and acclimation plasticity of the symbiont, which in the latter case is in part governed by cell size constraints (Suggett et al., 2015). These studies across natural light gradients have proved popular in understanding photoacclimation processes, whereas examining plasticity of photoacclimation at any one depth in response to natural environmental change (i.e., seasons) is comparatively understudied (Titlyanov et al., 2001; Hill and Ralph, 2005; Ulstrup et al., 2008; Winters et al., 2009; Sawall et al., 2014). Some evidence does suggest that processes operating within a species across a depth gradient also potentially operate over time; for example, the maximum photochemical efficiency $\left(F_{v} / F_{m}\right)$ for Symbiodinium in hospite of corals within shallow reefs are often driven to annual low yields in summer (Warner et al., 2002; Ulstrup et al., 2008). Most likely these lows in summer reflect long-term downregulation in response to warmer waters and high PAR in summer (Warner et al., 2002) that is also 
accompanied by an increase in photoprotection through nonphotochemical quenching (Ulstrup et al., 2008; Sawall et al., 2014; Louis et al., 2016). However, Hill and Ralph (2005) suggest that the same non-photochemical mechanisms for photoprotection to high-light exposure during the diel solar peak in key species of shallow water Great Barrier Reef corals are active across seasons and independent of temperature.

On balance, photoacclimation of Symbiodinium in hospite remains generally well-studied across space (i.e., depth) rather than through time. This is surprising given that stability of photochemistry is ultimately dependant on how effectively cumulative excitation pressure that builds over time can be processed. As such, photochemical strategies employed as seasons move toward annual temperature (and/or light) extremes may be particularly pivotal in dictating how coral taxa are differentially impacted by thermal events whilst operating toward the limit of their thermal tolerance (Ulstrup et al., 2008). We targeted 10 species of coral that encompass a diverse range of growth forms, reproductive modes, symbiont transmission strategies, Symbiodinium associations, and thermal tolerances at Heron Reef in the southern Great Barrier Reef (GBR, Australia). We initially contrast the extent of photoacclimation (and associated strategies with which absorbed excitation energy is processed) that operates in response to changing light and temperature between spring and summer seasons, and whether this is conserved across species. We subsequently consider the sensitivity of these same species to transient heat stress during summer and spring, and whether any differences potentially reflect alternate strategies of photoacclimation. In doing so, we show for the first time that these coral species vary widely in their strategy of light utilization during high-light doses in spring, but also share an inherent strategy during a low-light event in summer. Furthermore, we demonstrate coral-Symbiodinium symbioses that exhibit relative thermally tolerant photochemical function also maintain their strategy of light utilization across seasons.

\section{MATERIALS AND METHODS}

\section{Site Location and Retrieval of Seasonal Climate Data}

Heron Reef $\left(23^{\circ} 26^{\prime} 32.66^{\prime \prime} \mathrm{S}, 151^{\circ} 54^{\prime} 55.53^{\prime \prime} \mathrm{E}\right)$ is part of the Mackay Capricorn management area of the Great Barrier Reef Marine Park in the Southern Great Barrier Reef (Australia). Remotely-sensed weather information was extracted from the GIOVANNI online system for satellite derived climate data, which is maintained by NASA (http://disc.sci.gsfc.nasa.gov/ giovanni). Monthly area-averaged data between 2003 and 2016 collected by the Moderate Resolution Imaging Spectroradiometer (MODIS-aqua) were used in this study, including PAR at the ocean surface (Einstein $\mathrm{m}^{-2} \mathrm{~d}^{-1}$ ), and daytime sea surface temperature (SST, $\left.{ }^{\circ} \mathrm{C}\right)$. Satellite data were retrieved for Heron Reef using the bounding box function to define the area of interest. GPS co-ordinates of the bounding box (151.949, $-23.463,151.977,-23.443)$ were selected to match the location of relay poles RP1 and RP6 (spaning an area of $c a .8 \mathrm{~km}^{2}$ ) of the Heron Reef Integrated Marine Observing System (IMOS; Bainbridge et al., 2010). Supporting in situ information was retrieved from the Heron Reef IMOS network from all eight relay poles (RP1-8) that record high-resolution physical data, including above-water PAR (daily maxima and daily averages from RP8, $\mu$ mol photons $\mathrm{m}^{-2} \mathrm{~s}^{-1}$ ) and sea surface water temperature at $1-2 \mathrm{~m}$ depth (RP1-8, daily maxima and daily averages, ${ }^{\circ} \mathrm{C}$ ). This data is freely available under a Creative Commons 3.0 license (https://creativecommons.org/licenses/by/ 3.0/au/deed.en) via the Australian Institute of Marine Science (www.aims.gov.au), and was accessed on 18/10/2016 using the database provided rule-based quality control for eliminating outliers or errors.

Further environmental data that relate directly to the optical clarity of the water at Heron Reef (Michael et al., 2012) were accessed from the Bureau of Meteorology (BOM) Heron Island weather station (http://bom.gov.au) which is maintained by the Australian Government. Data for wind speed $\left(\mathrm{km} \mathrm{h}^{-1}\right)$, including; maximum daily gusts; wind speed at $09: 00 \mathrm{~h}$ and 15:00 $\mathrm{h}$; during the experimental periods in spring and summer (described below) were retrieved from BOM. All available data for total rainfall data $(\mathrm{mm})$ at Heron Island were also retrieved from BOM between 1959 and 2007. The diffuse attenuation coefficient $\left(\mathrm{K}_{\mathrm{d}}\right)$ of downwelling irradiance at $490 \mathrm{~nm}$, used to approximate seasonal changes in turbidity (Suggett et al., 2012), was collected from the same area of interest from MODIS (as above) during the experimental periods in spring and summer.

\section{Experimental Seasonal Context}

The Heron Reef system experiences significant seasonal variability in physical conditions (Kline et al., 2015), and therefore seasonal MODIS (remotely sensed) and IMOS (in situ) data were specifically considered for periods coinciding with our experiments (Figure 1). The first experiment was conducted between 28th October and 5th November (2015), which we refer to as "spring." The second experiment was conducted between 6th and 16th March (2016); whilst this second period is regarded as post-peak of the summer season, we refer to it as "summer" for the purposes of this study. When strictly considering monthly averaged temperature pooled through 2003 and 2015 (Figure 1), the MODIS data indicate that November and March are typically near equal in sea surface temperature (SST) at $26.4( \pm 0.2 \mathrm{SE})$ and $25.9( \pm 0.2){ }^{\circ} \mathrm{C}$, respectively, while the interceding months contain the annual maximum temperatures. However, the in situ IMOS data for SST pooled through 2008 and 2015 with higher temporal resolution indicate that the MODIS data likely over-estimate the actual SST here by $c a .1 .2^{\circ} \mathrm{C}$ in November, and under-estimate by $c a .0 .6^{\circ} \mathrm{C}$ in March (Figure 1). Strictly considering monthly averaged PAR (Figure 1), the monthly average irradiance of $665.3( \pm 20.3) \mu \mathrm{mol}$ photons $\mathrm{m}^{-2} \mathrm{~s}^{-1}$ coincide with the spring experiment in November, but following this month steadily decreases, reaching $457.7( \pm 13.9) \mu \mathrm{mol}$ photons $\mathrm{m}^{-2} \mathrm{~s}^{-1}$ in March. This trend is consistent across both MODIS and IMOS data sets. Thus, our two experimental periods contrast "spring" and "summer" as seasonal priming through (i) increases in temperature, and (ii) decreases in light availability. 


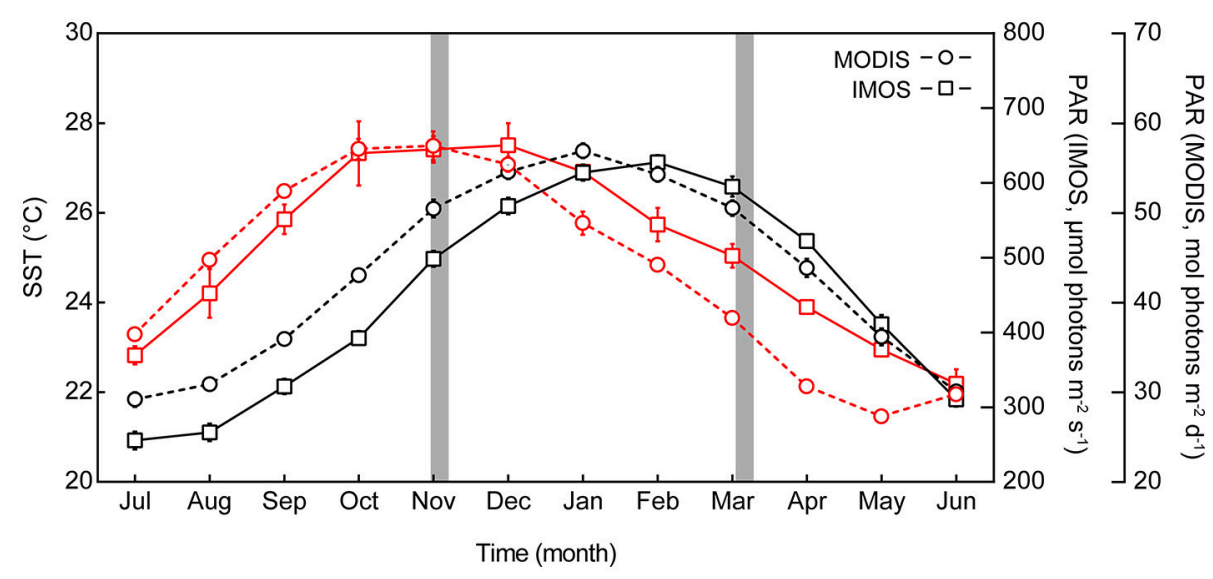

FIGURE 1 | Seasonal profile of sea surface temperature (SST) and photosynthetically active radiation (PAR) at Heron Reef. Monthly average SST (black lines, left axis) and monthly average PAR (red lines, right axes), for Heron Reef lagoon. Remote data sourced from the Moderate Resolution Imaging Spectroradiometer satellite (MODIS 2003-2016, circles) and the in situ Integrated Marine Observing System (IMOS 2009-2016, squares) represent monthly averages ( \pm SE) pooled across years including all available data. Experimental periods of this study are indicated by the gray areas.

Key photophysiological parameters of interest in this study (described in further detail in sections below) are known to acclimate in as few as 5-10 days (Anthony and HoeghGuldberg, 2003; Roth, 2014). Thus, we utilized the high-temporal resolution (daily) IMOS system for the 14 days pre-experiment (for both spring and summer) to capture the environment under which the photochemical pathways have primed, i.e., the environmental "acclimation history." The environmental conditions immediately following this during the experiment are referred to as "ambient." The summer period of this study in 2016 was conducted directly after Heron Reef was downgraded from "Bleach-Watch" status (low thermal stress for all of February) in the Coral Reef Watch models produced by the National Ocean and Atmospheric Administration (NOAA, http://coralreefwatch. noaa.gov/satellite/index.php).

\section{Species Collection and Maintenance}

Ten coral species were used in this study (Table 1); Acropora aspera; Acropora digitifera; Acropora formosa; Acropora millepora; Pocillopora damicornis; Montipora digitata; Isopora palifera; Stylophora pistillata; Porites cylindrica; and Porites lutea ( $N=4$ per species, $<2 \mathrm{~m}$ depth). All are considered common on the Great Barrier Reef (Madin et al., 2016) and are typically abundant on the shallow reef-flat and/or reef-crest of Heron Reef. These corals are typically dominated by Symbiodinium that broadly fall within clade C (LaJeunesse et al., 2003), and span a range of thermal tolerances that have previously been characterized in studies at Heron Reef (Table 1). Notably, corals containing Symbiodinium C15 (e.g., M. digitata, P. cylindrica, and $P$. lutea) are expected to be significantly more tolerant to transient heat stress than other species (Fitt et al., 2009; Fisher et al., 2012). Only coral colonies that visually appeared healthy (free of lesions or abnormal pigmentation) were selected for collection. No immediate visual signs of bleaching (i.e., significant paling of coral colonies) was observed on the reef during the spring or summer collections. Collected corals were transferred to Heron Island Research Station (The University of Queensland, Australia) and each colony was split into halves $(\sim 6 \times 2 \mathrm{~cm})$. All species (except $P$. lutea fragments which were mounted in a glass petri dish) were secured onto glass microscope slides using Selleys Epoxy (Selleys Pty Ltd., Australia). Coral collections were performed under the conditions of the Great Barrier Reef Marine Park Authority permits, numbered G15/37922.1 and G15/37538.1

Coral fragments were allowed to recover and acclimate for 5 days prior to experimentation in an unfiltered flow-through aquaria system under $50 \%$ of ambient light (using a neutral density shade-cloth) and a continuous flow of ambient lagoon seawater. This was deemed necessary (especially in spring) as the corals would otherwise experience artificially extreme lightdoses on a daily basis due to the limited depth (and size) of the holding tanks. After acclimation, corals were distributed to 8 replicate aquaria $(20 \mathrm{~L}, N=1$ fragment of each species per tank) also under $50 \%$ shaded natural light in a custom built open flow through system utilizing ambient lagoon seawater (minimum flow through of $0.5 \mathrm{~L} \mathrm{~min}^{-1}$ ). The water temperature within the system was recorded every $10 \mathrm{~min}$ with temperature loggers (HOBO pendant data loggers, Onset Computer Corp., Bourne, MA, USA) and/or temperature buttons (Thermochron, OnSolution, NSW, Australia). This same acclimation protocol and experimental system was used in both spring and summer.

\section{Seasonal Changes in Symbiodinium Photochemical Pathways}

PSII photochemistry of coral-hosted Symbiodinium cells was measured via chlorophyll $a$ fluorescence kinetics using a Pulse Amplitude Modulated (PAM) fluorometer (Diving PAM, Walz GmbH, Effeltrich, Germany, settings: MI: 12, Gain: 12, SI: 12, SW: 0.8 s, LC-INT: 3) with a glass optical fiber. Light response curves (applying actinic light to coral tissues incrementally in 
TABLE 1 | Coral species used in this study from the shallow reef-flat environments of Heron Reef.

\begin{tabular}{|c|c|c|c|c|}
\hline Coral species & Growth form & $\begin{array}{l}\text { Reproductive mode }+ \\
\text { symbiont transmission }\end{array}$ & $\begin{array}{l}\text { Known Symbiodinium } \\
\text { associations (ITS2) }\end{array}$ & Thermal tolerance $>31^{\circ} \mathrm{C}$ \\
\hline Acropora aspera & Branching (open) & Spawn + horizontal & C3 Hillyer et al., 2017 & $\begin{array}{l}\text { Sensitive Fisher et al., } 2012 \text { Sensitive } \\
\text { Middlebrook et al., } 2008\end{array}$ \\
\hline Acropora digitifera & Corymbose/digitate & Spawn + horizontal & C3 LaJeunesse et al., 2003 & ND \\
\hline Acropora formosa & Branching (open) & Spawn + horizontal & C3 LaJeunesse et al., 2003 & Sensitive Fisher et al., 2012 \\
\hline Acropora millepora & Corymbose & Spawn + horizontal & C3 LaJeunesse et al., 2003 & $\begin{array}{l}\text { Sensitive Hill et al., } 2012 \\
\text { Intermediate Fisher et al., } 2012\end{array}$ \\
\hline Pocillopora damicornis & Branching (closed) & Brood + vertical & $\begin{array}{l}\text { C1 LaJeunesse et al., } 2003 \\
\text { C1c LaJeunesse et al., } 2003 \\
\text { C33 Stat et al., } 2008 \\
\text { C42 Stat et al., } 2008\end{array}$ & Intermediate Hill et al., 2012 \\
\hline Montipora digitata & Branching (open) & Spawn + vertical & $\begin{array}{l}\text { C15 LaJeunesse et al., } 2003 \\
\text { C17 Fisher et al., } 2012 \\
\text { C73 Stat et al., } 2008\end{array}$ & $\begin{array}{l}\text { Tolerant Krueger et al., } 2015 \\
\text { Tolerant Fisher et al., } 2012\end{array}$ \\
\hline Isopora palifera & Branching (open) & Brood + horizontal & $\begin{array}{l}\text { C3 LaJeunesse et al., } 2003 \\
\text { D1 Stat et al., } 2008\end{array}$ & ND \\
\hline Stylophora pistillata & Branching (closed) & Brood + vertical & $\begin{array}{l}\text { C1 LaJeunesse et al., } 2003 \\
\text { C8a Sampayo et al., } 2007 \\
\text { C35 Sampayo et al., } 2007 \\
\text { C35a Sampayo et al., } 2007 \\
\text { C42 Sampayo et al., } 2007 \\
\text { C78 Sampayo et al., } 2007 \\
\text { C79 Sampayo et al., } 2007\end{array}$ & $\begin{array}{l}\text { Sensitive Hawkins et al., } 2015 \\
\text { Sensitive Fitt et al., } 2009\end{array}$ \\
\hline Porites cylindrica & Branching (closed) & Spawn + vertical & $\begin{array}{l}\text { C15 LaJeunesse et al., } 2003 \\
\text { C17 Fisher et al., } 2012\end{array}$ & $\begin{array}{l}\text { Tolerant Fisher et al., } 2012 \\
\text { Tolerant Fitt et al., } 2009\end{array}$ \\
\hline Porites lutea & Massive & Spawn + vertical & C15 Fisher et al., 2012 & Intermediate Fisher et al., 2012 \\
\hline
\end{tabular}

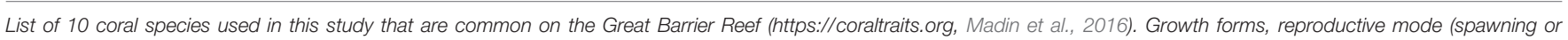

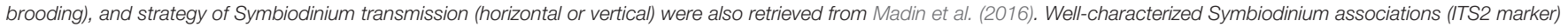

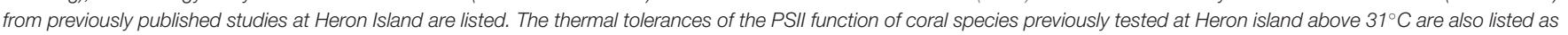
described in the respective citations. ND indicates no data.

steps of increasing irradiance) are classified according to the time duration of each light step. Rapid light curves [RLC, sensu Ralph and Gademann (2005); Serôdio et al. (2005)] apply light steps of short duration (e.g., 10, 20, 30 s, Perkins et al., 2010) and are widely used in coral photobiology, largely to maximize sample replication while underwater (e.g., Warner et al., 2010). Whilst RLCs provide limited time for photoprotective mechanisms to be maximally induced, steady-state light curves (SSLC) are longer in duration (e.g., $3.5 \mathrm{~min}$ of each light step) and are designed to allow the induction of heat-dissipation mechanisms to reach completion. However, assuming a strong diel profile of PSII photochemical efficiency in corals on shallow reef environments (Hill and Ralph, 2005), replicates (or species) may enter different states of acclimation if not sampled rapidly and thus SSLCs are not practical for comparisons of multiple field samples. Furthermore, as coral tissues migrate in response to high-light (Levy et al., 2003; Wangpraseurt et al., 2017b), the assumption that the optical properties related to the structure of the sample remain constant (Serôdio et al., 2006) may be violated during the long-duration of the SSLC and the retrieved fluorescence signals may become error-prone (as seen for corals in Lichtenberg et al., 2016). Suggett et al. (2015) demonstrated that RLCs (20 s light steps) and SSLCs (3.5 min light steps) generally resolve similar light utilization patterns across diverse taxa of Symbiodinium in culture, however it is unknown if Symbiodinium cells organized into the tissue layers of corals will show similar patterns (although both RLCs and SSLCs are equally limited in this regard). With these factors considered (and discussed in sections below), the use of RLCs are preferred in the present study to conduct all measurements within a narrow time-frame, and we interpret the findings within the limitations of the method. Importantly, we do not interpret the findings as absolute rates of electron transport in photosynthesis (Enríquez and Borowitzka, 2010; Warner et al., 2010) and we do not utilize the RLC as a substitute for a SSLC (Perkins et al., 2010). RLCs with 8 actinic light steps were conducted on low-light acclimated corals during the first $1.5 \mathrm{~h}$ of the morning light period ( $N=3$ technical replicates per fragment for $N=4$ biological replicates) to minimize the effect of nighttime reduction of the plastoquinone pool (Hill and Ralph, 2005). Actinic light levels (calibrated against a factory calibrated LI-192 quantum sensor, Li-Cor, Lincoln, NB, USA) of the RLC were 0 , $115,168,228,335,450,666,954,1,356 \mu \mathrm{mol}$ photons $\mathrm{m}^{-2} \mathrm{~s}^{-1}$, and $0,98,162,240,325,480,610,971,1,350 \mu \mathrm{mol}$ photons $\mathrm{m}^{-2} \mathrm{~s}^{-1}$ in spring and summer, respectively, and were delivered in $20 \mathrm{~s}$ intervals. All RLC measurements were conducted over 4-days, with one replicate per species per day. Distributing the RLCs over a 4-day experimental period was necessary to complete the technical replicates for each fragment within 
the naturally low-light acclimated state immediately following sunrise.

All RLCs were initiated with a dark measurement to provide the minimum and maximum dark acclimated fluorescence yields, $F_{o}$ and $F_{m}$, respectively, and all subsequent steps measure the minimum, and maximum fluorescence yields under actinic light, $F^{\prime}$ and $F_{m}{ }^{\prime}$, respectively. These parameters are then used to calculate the maximum $\left(F_{v} / F_{m}=\left[F_{m}-F_{o}\right] / F_{m}\right)$ and effective $\left(F_{q}^{\prime} / F_{m}{ }^{\prime}=\left[F_{m}{ }^{\prime}-F^{\prime}\right] / F_{m}{ }^{\prime}\right)$ photochemical efficiency. Whilst the latter term is often denoted as $\Phi_{P S I I}$, we use $F_{q}{ }^{\prime} / F_{m}{ }^{\prime}$ to be consistent with Hennige et al. (2008) and Suggett et al. (2012). A light-response curve for $F_{q}^{\prime} / F_{m}{ }^{\prime}$ was thus generated for each RLC and then fit to a model that characterizes the light-dependent quantum efficiency of PSII using least squares non-linear regression (Equation 1), described in Hennige et al. (2008).

$$
F_{q}^{\prime} / F_{m}^{\prime}=\left[\left(F_{q}^{\prime} / F_{m}^{\prime}{ }_{(\max )} E_{k}\right)\left(1-\exp \left(-E / E_{k}\right)\right)\right] / E
$$

Briefly, this model provides an estimate of the minimum saturating irradiance $\left(E_{k} \mu \mathrm{mol}\right.$ photons $\left.\mathrm{m}^{-2} \mathrm{~s}^{-1}\right)$ which describes the transition between the light-limited and the lightsaturated states of PSII (Hennige et al., 2008). Equation (1) also derives $F_{q}{ }^{\prime} / F_{m}{ }^{\prime}{ }_{\text {(max) }}$ (dimensionless) which is an alternate estimate of the maximum PSII photochemical efficiency, which can differ from the dark-acclimated maximum quantum yield of photosystem II $\left(F_{v} / F_{m}\right)$ depending on light history, see Suggett et al. (2012).

To calculate the poise of the photosystem and the activity of pathways of excitation energy transfer other than fluorescence, the extent of light dependant photochemical $([1-C]$, Equation 2) and non-photochemical quenching ([1 - Q], Equation 3) parameters were both derived from each RLC light step across seasons and species as follows.

$$
\begin{aligned}
& {[1-C]=\left(F_{m}{ }^{\prime}-F\right) /\left(F_{m}{ }^{\prime}-F_{o}{ }^{\prime}\right)} \\
& {[1-Q]=\left(F_{v}{ }^{\prime} / F_{m}{ }^{\prime}\right) /\left(F_{v} / F_{m}\right)}
\end{aligned}
$$

where $[1-C]$ is the same as $q P$ referred to in previous studies (Hennige et al., 2008; Oxborough et al., 2012), which assumes zero connectivity $(C)$ between adjacent reaction centers and represents the proportion of excitation energy used to drive photochemistry as the fraction of open reaction centers. [1 - Q] describes the dynamic non-photochemical quenching $(Q)$ that is equivalent to the excitation pressure over PSII (Iglesias-Prieto et al., 2004; Suggett et al., 2015). Use of [1 - Q] is preferred for our study over other calculations of non-photochemical quenching, [e.g., NPQ $\left.=\left(F_{m}-F_{m}{ }^{\prime}\right) / F_{m}{ }^{\prime}\right]$, since the product of $[1-C]$ and $[1-Q]$ account for the total energetic dissipation (effective photochemical efficiency) normalized to taxonomic differences in maximum photochemical efficiency, i.e., $\left(F_{q}{ }^{\prime} / F_{m}{ }^{\prime}\right) /\left(F_{v} / F_{m}\right)$ (see Suggett et al., 2015). These parameters decrease over the course of the RLC as they become active or are "utilized."

While all corals were collected from the same light environment ( $<2 \mathrm{~m}$ depth), and care was taken to avoid species at Heron Reef that are characterized as having comparatively thick tissue layers (e.g., Platygyra spp. or Pavona spp.), it is possible that differences in host pigmentation (Salih et al., 2000), alteration of light fields due to host macrostructure (Enríquez et al., 2005, 2017; Terán et al., 2010; Wangpraseurt et al., 2014), or even the aspect of the colony that fragments were removed from Brown et al. (2000), could potentially introduce variation in the acclimation states of the fragments. Thus, parameters generated from the RLC described below were normalized to $E_{k}$ to eliminate this source of variability (as per Hennige et al., 2008; Suggett et al., 2012). Examining parameters as $E / E_{k}$ rather than $E$ allows the differences in photoacclimation to be viewed independent of how photosynthetically usable radiation varies between species, and provides an indication of how mechanisms associated with regulating light-limited (below $E_{k}$ ) or light-saturated (above $E_{k}$ ) PSII are preferentially modified to optimize toward $E_{k}$ (Hennige et al., 2008).

Both $[1-C]$ and $[1-Q]$ were analyzed against the normalized values of $E / E_{k}$ and assessed with non-linear regression using a standard one phase decay model in Graphpad Prism (version 6). Replicates tests (Graphpad Prism version 6) that test for an inadequate model fit were performed on every curve and confirmed that the one-phase decay model adequately described all quenching curves for all species across both seasons $(p>0.05)$, except for $A$. millepora $[1-C]$ in spring which did not fit the one phase decay model and was instead fit to a linear model $\left(R^{2}=\right.$ $0.76)$. For every curve (each representing the mean of 4 replicates) the values of $[1-C]$ and $[1-Q]$ where $E / E_{k}=1$ (i.e., at the minimum saturating irradiance) were interpolated.

\section{Thermal Stress Assay and Monitoring of PSII Photochemical Efficiency}

Following the completion of the RLC described above in the nonstressed condition, half of the experimental tanks $(N=4)$ were subjected to changes in temperature to induce transient thermal stress, and the remaining experimental tanks $(N=4)$ were unchanged and served as ambient controls with continuous flow of ambient lagoon seawater. Our approach aimed to maximize synchronicity and equivalency of the ramping profiles in spring and summer (Figure S1) and reach equivalent end-points in temperature. In spring, temperature was increased from $26^{\circ} \mathrm{C}$ in $1^{\circ} \mathrm{C}$ increments daily to reach the target treatment temperature of $32^{\circ} \mathrm{C}$, and then was held for a further 3 days. $32^{\circ} \mathrm{C}$ was selected as an environmentally relevant upper limit as the single warmest day recorded by the IMOS network (measured across all RP) reached a maximum of $32.55^{\circ} \mathrm{C}$ (21st February 2009). In the summer experiment, the ambient lagoon was naturally fluctuating between 26 and $28^{\circ} \mathrm{C}$ on a diel basis and thus to synchronize the profile with spring, treatment tanks were allowed to fluctuate for the first day under which spring ramped from 26 to $27^{\circ} \mathrm{C}$, and then the profiles were synchronized from 28 to $32^{\circ} \mathrm{C}$ and increased in $1^{\circ} \mathrm{C}$ increments daily (Figure S1). Temperature was increased by pre-heating continuous flow-through lagoon seawater in a separate sump (200 L) with two custom built, thermostat controlled $\left( \pm 0.1^{\circ} \mathrm{C}\right)$ submersible heaters $(300 \mathrm{~W})$. Treatment water was pumped from this sump to aquaria at a flow rate matching the flow-through of ambient aquaria. 
During the temperature ramp and maintenance at $32^{\circ} \mathrm{C}$, darkacclimated maximum quantum yield of photosystem II $\left(F_{v} / F_{m}\right)$ was measured twice every day for every coral fragment to monitor for changes in photochemical efficiency (as per Oliver and Palumbi, 2011; Suggett et al., 2012); once in the first hour following sunrise ( $c a .07: 00 \mathrm{~h}$ local time) and once again in the evening during the first hour following sunset (ca. 19:00 h local time; $N=3$ technical replicates per fragment). An inverted exponential function (Equation 4, as per Vieira et al., 2009) was used to describe the decrease in $F_{v} / F_{m}$ through time as follows.

$$
F_{v} / F_{m}=F_{v} / F_{m(0)}-e^{-\mathrm{S}+\mathrm{kx}}
$$

where $F_{v} / F_{m}$ is expressed as $\%\left(\% F_{v} / F_{m}\right.$, relative to untreated fragments), $F_{v} / F_{m}(0)=\% F_{v} / F_{m}$ prior to thermal stress (i.e., $x=0), x=$ time (d), $S$ is a parameter related to the length of the period during which $\% F_{v} / F_{m}$ remains stable, and $k\left(\mathrm{~d}^{-1}\right)$ is the rate constant that quantifies the rate of $\% F_{v} / F_{m}$ decrease. The minimum (typically reached at the final measurement) darkacclimated maximum quantum yield of photosystem II reached during exposure to heat stress, will be referred to as $\% F_{v} / F_{m}(\min )$.

\section{Statistical Analyses}

Environmental variables were compared between seasons using unpaired two tailed $t$-tests, assuming unequal variances which were accounted for with Welch's correction. This same statistical test was used to analyse the pooled photoacclimation response ( $E_{k}$ and $F_{q}^{\prime} / F_{m}^{\prime}(\max )$ of all coral species when comparing between spring and summer. To identify specific differences across seasons and species two-way ANOVA was used to investigate the interactions between season (two levels) and species (10 levels) on derived values of $E_{k}$ and $F_{q}{ }^{\prime} / F_{m}{ }^{\prime}(\max )$, with Sidak's multiple comparisons post hoc tests to locate significant differences. All statistical tests were performed in Graphpad Prism (version 6) against an $\alpha$ of 0.05 . To identify functional groupings of corals based on all derived components of the light response curves and thermal tolerance of PSII function, cluster analysis and multidimensional scaling (MDS) were performed with $E_{k} ; F_{q}^{\prime} / F_{m}^{\prime}{ }_{(\max )} ;[1-C]:[1-Q]$ at $E / E_{k}=1$; and $\% F_{v} / F_{m(\min )}$, with PRIMER-E v6.1 (PRIMER-E Ltd, Ivybridge, Devon, UK). All values were standardized using a square root transformation using PRIMER-E and correlations were drawn based on Pearsons distance. An analysis of similarity (ANOSIM) was used to determine whether the corals separated by MDS ordination significantly differed between seasons.

\section{RESULTS}

\section{Spring and Summer Environmental Conditions in the Heron Lagoon}

Ambient SST during the experiments in spring (2015) and summer (2016, IMOS in situ) closely matched the typical SST for October-November and February-March (2009-2016; Table 2). SST increased significantly from spring through summer as expected; daily averages were $24.2^{\circ} \mathrm{C}( \pm 0.7)$ and $26.9^{\circ} \mathrm{C}( \pm 0.3)$ during the spring and summer experiments, respectively. Maximum ambient temperatures reached across these periods were 27.3 and $30.2^{\circ} \mathrm{C}$, respectively (Table 2, Figure S2). Ambient PAR for spring and summer were also consistent with previous years (Table 2, Figure S2), whereby ambient daily average PAR during spring was $541.5( \pm 148.2) \mu \mathrm{mol}$ photons $\mathrm{m}^{-2} \mathrm{~s}^{-1}$ and was significantly lower during the summer at 442.8 $( \pm 142.9) \mu$ mol photons $\mathrm{m}^{-2} \mathrm{~s}^{-1}$ (unpaired two tailed $t$-test with Welch's correction, $t_{(43)}=3.10$ and $t_{(38)}=2.4$, respectively, $p<0.05)$. Maximum daily PAR values during these periods were 2091.3 and $2004 \mu \mathrm{mol}$ photons $\mathrm{m}^{-2} \mathrm{~s}^{-1}$, respectively. This pattern appears to be driven by consistent levels of PAR (i.e., days to weeks) in spring, whereas summer months were frequently punctuated by multiple events of comparatively low PAR (i.e., storm events, Figure S2). Indeed, the acclimation history directly preceding the summer experiment included a significant weather event that lowered the average daily and average maximum PAR to 124 and $560.3 \mu \mathrm{mol}$ photons $\mathrm{m}^{-2}$ $\mathrm{s}^{-1}$, respectively (Figure S2). This pattern of decreasing PAR from spring through summer appears seasonally typical and supported by long-term trends gathered from MODIS (20032016; Figure 1).

Further physical changes that play a significant role in modulating in-water PAR include the diffuse attenuation coefficient $\left(\mathrm{K}_{\mathrm{d}}\right)$ of downwelling irradiance, which is used to approximate changes in seawater turbidity (Suggett et al., 2012), elevated wind speeds [which are known to increase $K_{d}$ at Heron Reef (Michael et al., 2012)], and monthly rainfall. Heron Reef is subjected to significantly faster wind speeds and nearly three-fold greater rainfall in summer (Figure S2). However, this more extreme weather of summer is not reflected in seasonal differences in the remotely-sensed $K_{d}(490)$ retrieved from the MODIS instrument (Figure S3).

\section{Light Dependant Response of Symbiodinium Photochemistry}

Eqn. 1 produced a robust description of the light dependant response of $F_{q}^{\prime} / F_{m}^{\prime}$ across species and seasons $\left(R^{2} c a .0 .9\right)$, except for $A$. aspera and $M$. digitata in spring $\left(R^{2}=0.76\right.$ and 0.65 , respectively) although values for $E_{k}$ and $F_{q}{ }^{\prime} / F_{m}{ }^{\prime}$ (max) were still within the range retrieved for all species. Significant seasonal changes in $E_{k}$ (Figure 2) were evident for all species. In spring, the pooled average of $E_{k}$ across all 10 species was $534.1( \pm 67.3) \mu \mathrm{mol}$ photons $\mathrm{m}^{-2} \mathrm{~s}^{-1}$, and in summer decreased $>2$-fold to 227.5 ( \pm 28.5$) \mu \mathrm{mol}$ photons $\mathrm{m}^{-2} \mathrm{~s}^{-1}$ [unpaired two tailed $t$-test with Welch's correction, $t_{(9)}=17.77, p<$ $0.01]$. These values of minimum saturating irradiance are thus consistent with the differences in acclimation history between spring and summer experiments (Table 2, Figure S2). A twoway ANOVA of species $\times$ season revealed significant effects of each factor $\left[F_{(9,59)}=2.835, p<0.01\right.$, and $F_{(1,59)}=345.2$, $p<0.0001$, respectively] and Sidak's multiple comparisons tests confirmed that all comparisons of species from spring to summer had significantly lower $E_{k}$ (all multiple comparison tests $p<0.05)$. The largest change in $E_{k}$ between seasons was for A. aspera decreasing from $652.9( \pm 75.4) \mu \mathrm{mol}$ photons $\mathrm{m}^{-2} \mathrm{~s}^{-1}$ in spring to $244( \pm 10.4) \mu \mathrm{mol}$ photons $\mathrm{m}^{-2} \mathrm{~s}^{-1}$ in summer. In contrast, the smallest changes in $E_{k}$ were observed 
TABLE 2 | The physical environment of Heron Reef in spring and summer.

\begin{tabular}{|c|c|c|c|c|c|c|}
\hline & \multicolumn{3}{|c|}{ Spring } & \multicolumn{3}{|c|}{ Summer } \\
\hline Daily average & $24.0( \pm 1.2)$ & $23.5( \pm 0.7)$ & $24.2( \pm 0.9)$ & $26.8( \pm 0.8)$ & $27.3( \pm 0.4)$ & $26.8( \pm 0.3)$ \\
\hline Daily maximum & $25.2( \pm 1.3)$ & $24.9( \pm 1.2)$ & $25.5( \pm 1.1)$ & $27.8( \pm 1.0)$ & $28.4( \pm 0.7)$ & $27.7( \pm 0.5)$ \\
\hline \multicolumn{7}{|c|}{ PAR ( $\mu \mathrm{mol}$ photons $\left.\mathrm{m}^{-2} \mathrm{~s}^{-1}\right)$} \\
\hline Daily maximum & $2090.5( \pm 180.4)$ & $2019.1( \pm 97.4)$ & $1930.8( \pm 224.6)$ & $1982.5( \pm 516.4)$ & $1777.8( \pm 391.8)$ & $1700.3( \pm 424.9)$ \\
\hline
\end{tabular}

In situ physical data retrieved from the Heron Reef IMOS network (from all eight relay poles). Data include above-water photosynthetically available radiation (PAR, $\mu$ mol photons $m^{-2}$ $\mathrm{s}^{-1}$, daily maxima and daily averages) and sea surface water temperature at $1-2 \mathrm{~m}$ depth ( ${ }^{\circ} \mathrm{C}$, daily maxima and daily averages). All available data (daily measurements between 2009 and 2016) were used to characterize the typical conditions for spring (October-November) and summer (February-March). The acclimation history reflects the $14 d$ period directly preceding the spring (2015) and summer (2016) experiments. The ambient environmental conditions during the experiment are also listed. Values represent means for the period \pm 1 SD. These data were accessed via the Australian Institute of Marine Science (www.aims. gov.au).

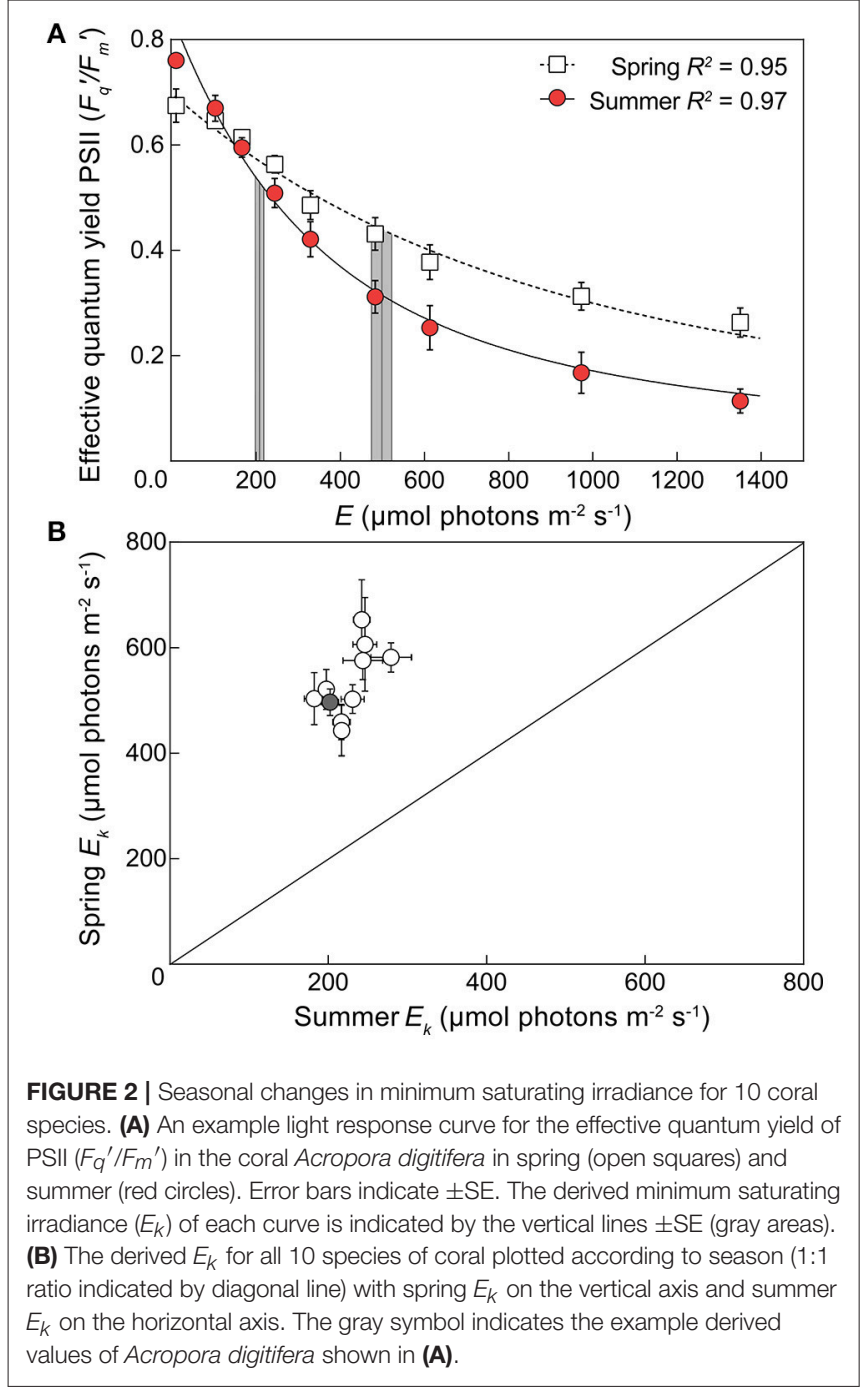

for P. cylindrica, decreasing from $442.8( \pm 47.8) \mu \mathrm{mol}$ photons $\mathrm{m}^{-2} \mathrm{~s}^{-1}$ to $218.5( \pm 8.9) \mu \mathrm{mol}$ photons $\mathrm{m}^{-2} \mathrm{~s}^{-1}$ between seasons.
Values for the derived maximum PSII photochemical efficiency $F_{q}{ }^{\prime} / F_{m}{ }^{\prime}{ }^{\prime(\max )}$ (dimensionless) also differed significantly between seasons and when averaged across all species increased from $0.68( \pm 0.01)$ in spring to $0.77( \pm 0.02)$ in summer [Figure S4, unpaired two tailed $t$-test with Welch's correction, $t_{(12)}=$ 4.94, $p<0.001]$. This is supported by the measured values of $F_{v} / F_{m}$ which also increase across seasons (Figure S5). A two-way ANOVA of species $\times$ season revealed a significant interaction between factors $\left[F_{(9,59)}=2.147, p<0.05\right]$; however, Sidak's multiple comparisons tests confirmed that this was not driven by a consistent response across all species (Figure S4). For example, whilst $M$. digitata, $P$. lutea, $P$. cylindrica, and S. pistillata, exhibited significant changes in $E_{k}$, no corresponding significant shift in $F_{q}{ }^{\prime} / F_{m}{ }^{\prime}(\max )$ was observed (Figure S4). However, all other species demonstrated a shift in $F_{q}{ }^{\prime} / F_{m}{ }^{\prime}$ (max) with an increase in summer (Sidak's multiple comparisons tests $p<0.05$ ), and the largest change in $F_{q}{ }^{\prime} / F_{m}{ }^{\prime}(\max )$ of 0.14 (dimensionless) between seasons was observed in A. digitifera. Overall, these general complimentary responses for $E_{k}$ and $F_{q}{ }^{\prime} / F_{m}{ }^{\prime}(\max )$ are consistent with acclimation to the decrease of light availability (Hennige et al., 2008; Suggett et al., 2012) that appears typical between spring and summer, including our 2015/16 sampling season (above, Table 2).

\section{Seasonal Changes in Light Dependant Dynamic Quenching}

Values derived for $[1-C]$ at $E / E_{k}=1$ pooled across all species differed significantly between seasons [unpaired two tailed $t$-test with Welch's correction, $t_{(10)}=4.675, p<0.001$ ], decreasing from $0.79( \pm 0.02)$ in spring to $0.72( \pm 0.01 \mathrm{SE})$ in summer. Similarly, the derived $[1-Q]$ at $E / E_{k}=1$ pooled across all species also differed significantly between seasons [unpaired two tailed $t$ test with Welch's correction, $t_{(13)}=7.56, p<0.001$ ], increasing from $0.79( \pm 0.02)$ in spring to $0.94( \pm 0.01)$ in summer. As such, at the light intensity at which electron transfer rates "saturate" $\left(E / E_{k}=1\right)$, corals generally shifted toward increased reliance of photochemical over non-photochemical quenching from spring into summer as light availability decreased. In fact, three distinct quenching patterns previously described for 
Symbiodinium isolates (Suggett et al., 2015) were observed in spring. "Normal quenching," where $[1-C]$ and $[1-Q]$ are utilized equally, $P$. damicornis and $A$. digitifera; preferential photochemical quenching, where the ratio of $[1-C]$ to $[1-Q]$ $<1$ for P. lutea, P. cylindrica, S. pistillata, and M. digitata; and preferential non-photochemical quenching, where the ratio of $[1-C]$ to $[1-Q]>1$ for A. aspera, A. formosa, A. millepora, and $I$. palifera. However, all coral species switched to preferential utilizing $[1-C]$ in summer (Figure 3). The largest seasonal shift in the ratio of $[1-C]$ to $[1-Q]$ at $E / E_{k}=1$ was for $A$. formosa (1.23 in spring, decreased to 0.73 in summer), whereas the smallest shift was for $S$. pistillata (0.88 in spring, decreased to 0.79 in summer).

\section{PSII Photochemical Efficiency during Transient Heat Stress Assays}

Corals subjected to transient heat stress typically exhibited comparable $\% F_{v} / F_{m(\min )}$ across spring and summer, except for $P$. damicornis and S. pistillata (Figures $4 \mathrm{E}, \mathbf{H}$ ). S. pistillata suffered total dysfunction in spring, i.e., chlorophyll fluorescence was below the levels of detection (not able to measure $F_{o}$ ), representing the strongest reaction of all species to transient heat stress. In contrast, $S$. pistillata was less sensitive in summer with $\% F_{v} / F_{m(\min )}$ reaching $41.12( \pm 13.91)$ relative to ambient fragments; as such, $S$. pistillata was the only species to show significantly enhanced thermal tolerance from spring to summer. $P$. damicornis exhibited an opposite response whereby $\% F_{v} / F_{m(\min )}$ reached $75.31( \pm 8.85)$ relative to ambient fragments in spring, but had a heightened sensitivity in summer $\left[\% F_{v} / F_{m(\min )}\right.$ was reduced to $19.91( \pm 8.89)$ relative to ambient fragments].

PSII photochemical efficiency of $M$. digitata and $P$. lutea was tolerant to transient heat stress across both seasons (Figures 4F,I). However, in summer, P. lutea fragments raised to $32^{\circ} \mathrm{C}$ demonstrated increased diel variability (i.e., morning vs. evening $\left.\% F_{v} / F_{m}\right)$ relative to ambient fragments. All other coral species exhibited compromised PSII photochemical efficiency via heat stress for both seasons. Parameters retrieved by the inverted exponential function fit to changes in $\% F_{v} / F_{m}$ (Equation 4, Table S1) indicate that PSII photochemical efficiency for multiple species declined earlier in summer than in spring (i.e., $S_{\text {summer }}<S_{\text {spring }}$ ), however, the rate of decline (once it began) was comparatively more rapid in spring than in summer (i.e., $k_{\text {summer }}<k_{\text {spring }}$ ). For example, for $A$. aspera, $S$ (dimensionless) was $5.18( \pm 3.26)$ in spring, but declined to $1.64( \pm 0.53)$ in summer, whereas $k\left(\mathrm{~d}^{-1}\right)$ declined from $0.94( \pm 0.40) \mathrm{d}^{-1}$ to $0.58( \pm 0.06) \mathrm{d}^{-1}$ from spring to summer (Table S1, Figure 4A). Despite these minor seasonal differences in kinetics of PSII photochemical efficiency, $\% F_{v} / F_{m(\min )}$ for $A$. aspera after $3 \mathrm{~d}$ at $32^{\circ} \mathrm{C}$ was not significantly different across seasons [83.33 $( \pm 8.43)$ in spring vs. $75.76( \pm 4.19)$ in summer]. This same pattern of an earlier, more gradual decline in PSII photochemical efficiency during the summer experiment was also seen in $A$. digitifera, A. millepora, and P. cylindrica (Table S1). A. formosa and $I$. palifera were more sensitive to transient heat stress than the other Acroporid species, and $\% F_{v} / F_{m(\min )}$ reached 44.63

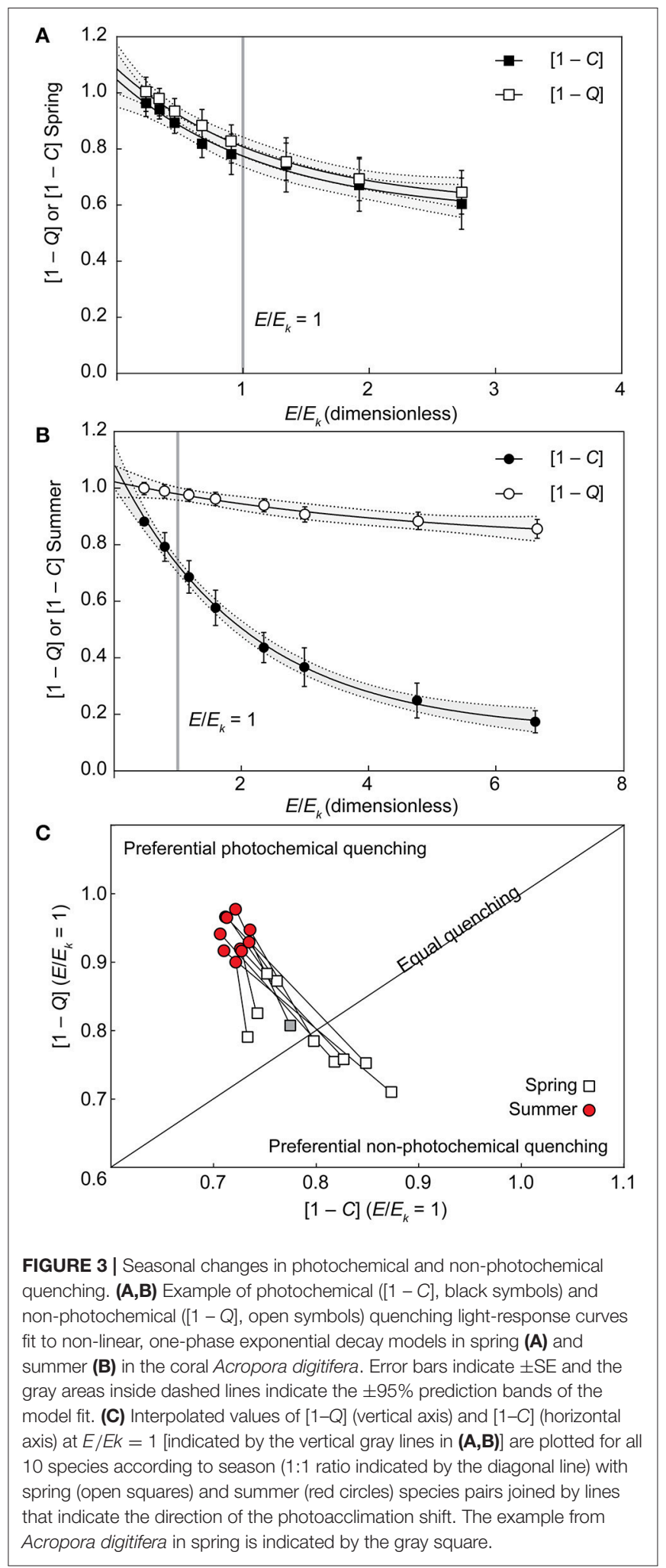

$( \pm 25.81)$ and $50.75( \pm 23.43) \%$ for the two species respectively in spring compared to $56.83( \pm 19.87)$ and $60.88( \pm 20.53) \%$ in summer. Additionally, A. formosa and I. palifera demonstrated 

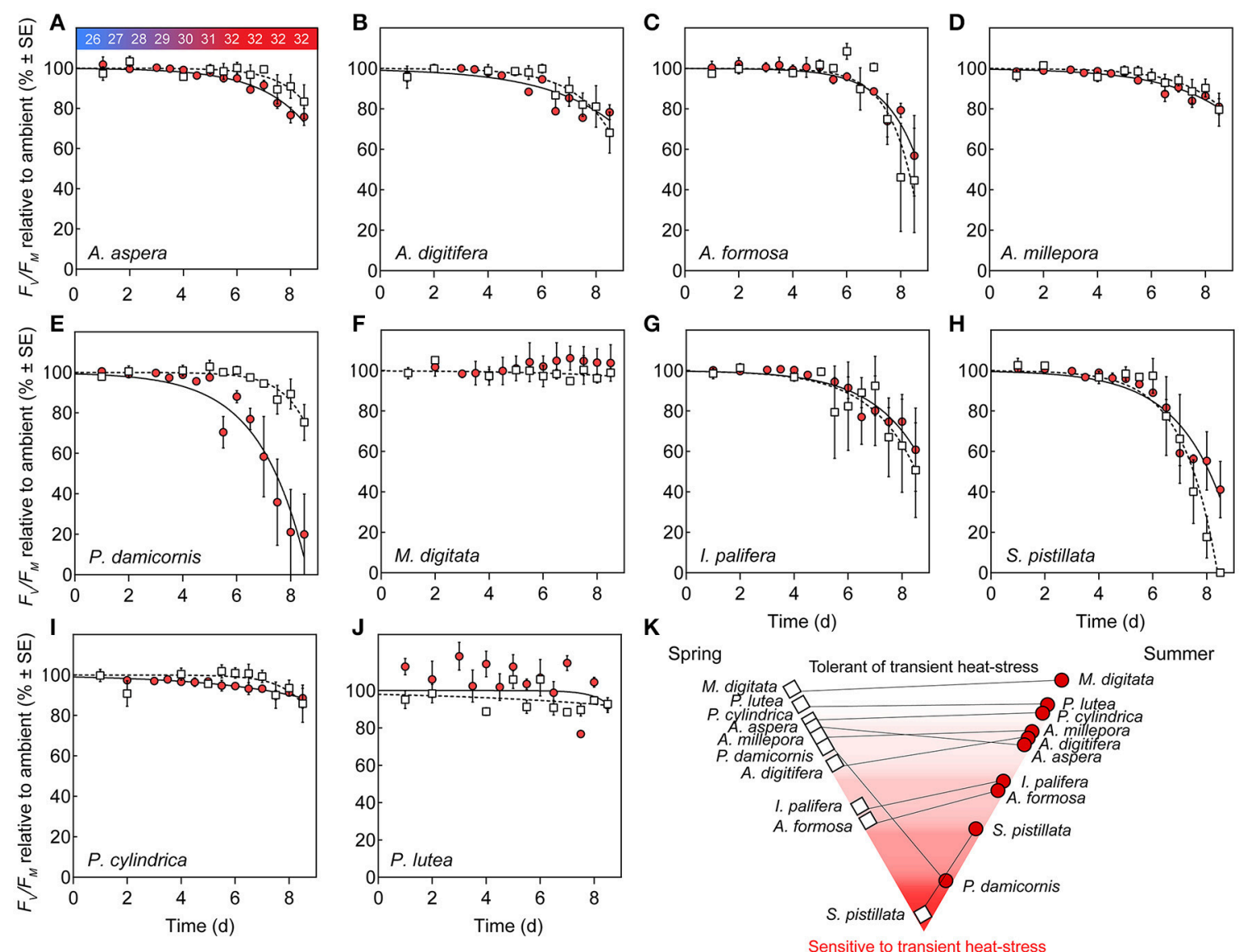

FIGURE 4 | Photosystem II (PSII) function under transient heat stress. (A-J) Species-specific declines in maximum PSII quantum yield (\% $\left.F_{V} / F_{m}\right)$ of corals under a thermal stress experiment expressed relative to ambient controls (\%) at each corresponding time point in spring (open squares) and summer (red circles). Lines represent the non-linear regression, inverted exponential fit in spring (hashed lines) and summer (solid lines). Values represent means $(N=4) \pm S E$. (K) Pyramid graph of the hierarchy of thermal tolerance from most tolerant (top) to the most sensitive species (bottom). Horizontal lines between spring (left, open squares) and summer (right, red circles) indicate the direction of change in minimum dark-acclimated quantum yield of photosystem II reached during exposure to heat stress as $\% F_{V} / F_{m(\min )}$ across seasons.

high inter-fragment variability. For example, the $\% F_{v} / F_{m}$ of $I$. palifera exposed to transient heat stress in spring ranged from 0.62 to 0.15 (dimensionless) across all four replicates.

\section{Functional Diversity in Photobiology across Species and Seasons}

All of the derived photophysiological parameters, including $E_{k}$, $F_{q}^{\prime} / F_{m}^{\prime}{ }_{(\max )},[1-C]$ and $[1-Q]$ at $E / E_{k}=1$, as well as

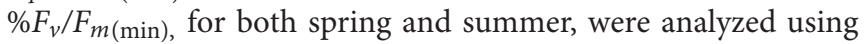
MDS to examine functional differences across species. ANOSIM further confirmed the significant separation of photobiology across seasons (Figure 5, global $R=0.88, p<0.001$ ), whereby separation of seasonal clusters was driven primarily by the RLC-derived parameters (horizontal vectors of $E_{k}, F_{q}{ }^{\prime} / F_{m}{ }^{\prime}(\max )$, $[1-C]$ and $[1-Q]$, Figure 5). Within each season, the ordinations of individual species did not cluster exclusively according to growth form, host taxonomy, or known symbiont associations (Table 1). For example, in spring, three distinct genera (Acropora, Porites, and Montipora) cluster together at
97\% similarity. Species within each season were thus largely ordinated according to the response of PSII photochemical efficiency to heat stress (vertical vector of $\% F_{v} / F_{m(\min )}$ ) with the most thermally tolerant species ( $M$. digitata and $P$. lutea) clustered together at $97 \%$ similarity in both seasons. S. pistillata was the most dissimilar to all other species ( $<80 \%$ similarity) and this is primarily driven by the complete dysfunction in response to temperature [i.e., $\% F_{v} / F_{m(\min )}=0$ ], rather than differences in the non-stressed photobiology (above). For species that survived the transient heat stress (i.e., excluding $S$. pistillata), the only RLC parameter demonstrating a significant linear relationship with PSII photochemical efficiency under stress was the extent of lightdependant dynamic quenching (Figures 5B,D). Specifically, a negative linear relationship between $\% F_{v} / F_{m(\min )}$ and $[1-C]$ at $E / E_{k}=1\left(R^{2}=0.48, p<0.05\right)$, and a positive linear relationship between $\% F_{v} / F_{m(\min )}$ and $[1-Q]$ at $E / E_{k}=1$ $\left(R^{2}=0.50, p<0.05\right)$, indicating that species inherently primed to preferentially employ greater photochemical over nonphotochemical quenching during non-stressed conditions also 

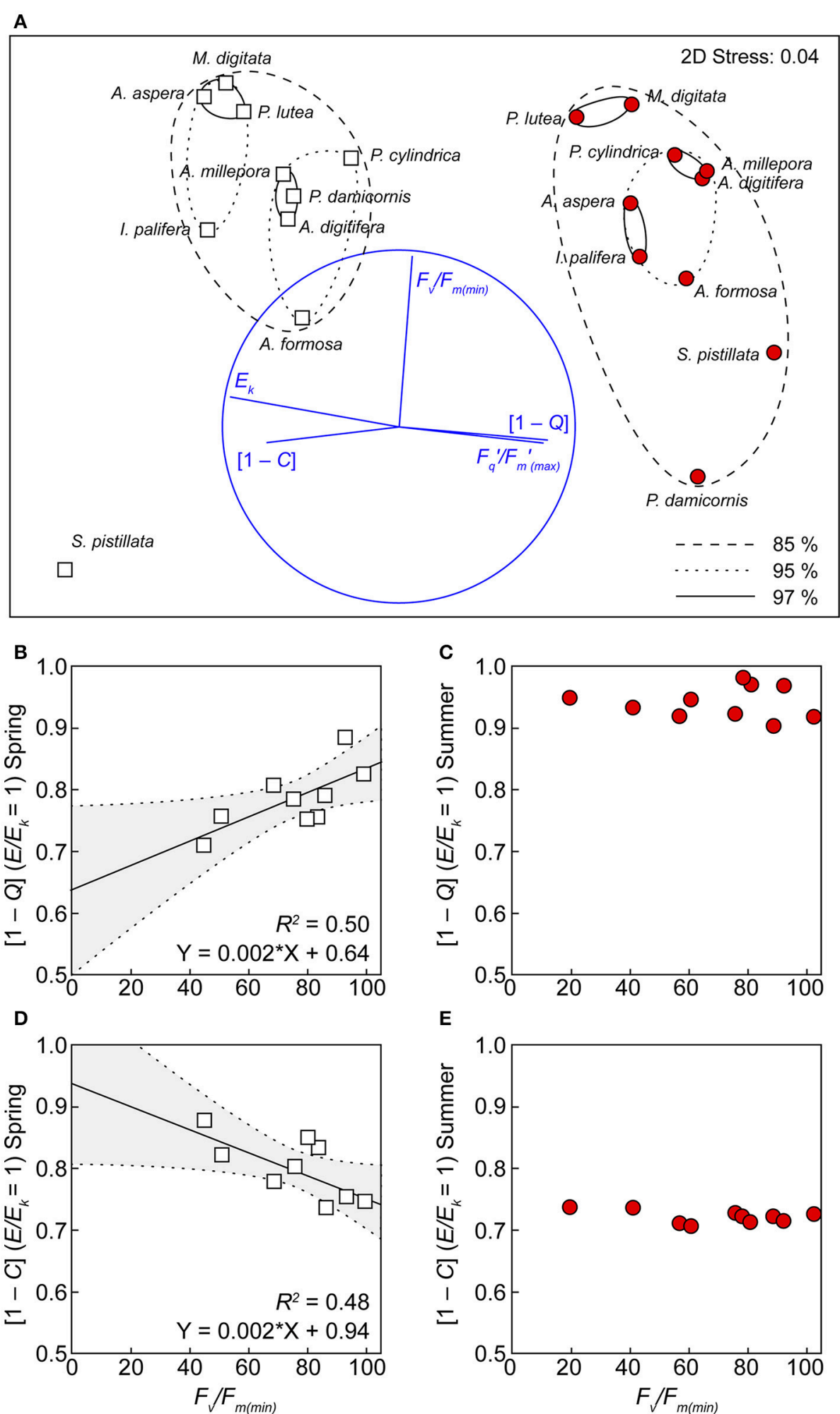

FIGURE 5 | Functional groupings according to photochemistry and thermal tolerance. (A) Multi-dimensional scaling (MDS) analysis, using the derived values of $E_{k}$, $F_{q^{\prime}} / F_{m}^{\prime}{ }_{\text {(max) }}$ (dimensionless), [1 $\left.-C\right]$ and [1-Q] at $E / E_{k}=1$, and $\% F_{V} / F_{m \text { (min) }}$ in both spring (white squares) and summer (red circles). Clusters represent 85 (hashed ovals), 95 (dotted ovals), and 97 (solid ovals) \% similarity (based on a Bray-Curtis dissimilarity matrix) between species. Significant linear correlations between [1 - Q] (B), [1 - C] (D) and \% $F_{V} / F_{m(\min )}$ are indicated by lines with $95 \%$ confidence band (gray areas) of the fit. This correlation is absent for the same parameters in summer (C,E). 
have PSII that are more thermally tolerant. However, this linear relationship was absent in summer (Figure 5).

\section{DISCUSSION}

Our study from the shallow-reef flat environment of Heron lagoon captured photochemical seasonal low-light acclimation from spring to summer across all coral species. Speciesindependent reductions in the minimum PSII saturating irradiance $\left(E_{k} \mu \mathrm{mol}\right.$ photons $\left.\mathrm{m}^{-2} \mathrm{~s}^{-1}\right)$ were consistent with seasonal reductions in PAR (i.e., $E / E_{k}$ approaching 1 ), and reflected a general shift to preferential utilization of $[1-C]$ (i.e., increased reliance on linear electron transport), which is expected as Symbiodinium acclimate toward low-light (Ragni et al., 2010; Suggett et al., 2015). Whilst such acclimation did not reorganize species hierarchy of thermal tolerance across seasons (except $S$. pistillata and $P$. damicornis), the strategy for dealing with light energy was unchanged for thermally tolerant species across seasons. We discuss how these findings expand our understanding of Symbiodinium photobiology and how such studies can potentially be used to identify diagnostics of thermal susceptibility under non-stressed conditions.

Symbiodinium spp. use various acclimation processes to increase their photosynthetic capacity and inhabit light-reduced habitats (e.g., mesophotic reefs or cryptic habitats), commonly reflected by reducing $E_{k}$; for example, acclimation from open, high-light habitats to light-reduced reef walls and caves (Montipora monasteriata at Wistari Reef, neighboring Heron Reef, Anthony and Hoegh-Guldberg, 2003), and with increasing depth (Madracis spp., Curacao, Frade et al., 2008); and across both clear and turbid sites (Porites lutea, Indonesia, Hennige et al., 2008). In the latter case, these trends shift in parallel with increases in $F_{q}{ }^{\prime} / F_{m}{ }^{\prime}(\max )$ (Hennige et al., 2008). Such acclimation can in fact be described by a linear function with changing optical depth (Hennige et al., 2008) until corals inhabit extreme light regimes (see Suggett et al., 2012). Our data from spring to summer are thus entirely consistent with this classical view of a reduction in $E_{k}$ and increase in $F_{q}{ }^{\prime} / F_{m}{ }^{\prime}(\max )$ indicating that the same photoacclimation processes that are well-described to operate across space, also operate through time.

In contrast to our observations, Ulstrup et al. (2008) previously demonstrated that $E_{k}$ is greater in summer (January) than in winter (July), especially for the shade-adapted sides of branches, for P. damicornis and Acropora valida at Heron Reef. However, this is not entirely at odds with our findings, as without data for the interceding months in spring, it is not possible to ascertain if corals examined by Ulstrup et al. (2008) cycled through a period of spring high-light acclimation. Immediately prior to and during the first days of our summer experiment, where average daily PAR levels (above water, IMOS network) dropped below $300 \mu \mathrm{mol}$ photons $\mathrm{m}^{-2} \mathrm{~s}^{-1}$ due to a significant weather event. The kinetics of photoacclimation in corals in response to stochastic low-light events have not been explored extensively for the corals used in our study; however, the coral Turbinaria mesenterina can exhibit changes in $E_{k}$ to changes in light levels in as few as 5-10 d (Anthony and Hoegh-Guldberg, 2003). Roth et al. (2010) also demonstrated that maximum quantum PSII yields increase in response to low-light conditions within a period of 5-10 d for the coral Acropora yongei. Such relatively rapid timeframes suggest that our $E_{k}$ and $F_{q}^{\prime} / F_{m}^{\prime}(\max )$ acclimation could therefore perhaps reflect a chance capturing of a stochastic low-light acclimation event, exacerbating any typical seasonal response that might have occurred. Such experiments would thus benefit from frequent sampling intervals (ideally daily measurements), to tease apart seasonal vs. stochastic weather acclimation. These challenges aside, we still observed an acclimation response consistent with changes in light availability across seasons and thus a basis to examine different acclimation states in the context of thermal sensitivity.

Our observed changes in $E_{k}$ [and $F_{q}^{\prime} / F_{m}{ }^{\prime}$ (max)] reflect the seasonal light environment; however, the apparent synergy between light and temperature in bleaching stress (Jones et al., 1998; Mumby et al., 2001; Anthony et al., 2007) indicate the potential role of factors other than light (i.e., temperature) in driving changes in the saturation of PSII reaction centers. $E_{k}$ is governed by changes in both light harvesting and utilization (Frade et al., 2008; Hennige et al., 2008; Suggett et al., 2012); however, the maximum rate of linear electron transport is further constrained by downstream processes, including $\mathrm{CO}_{2}$ limitation and the kinetics of enzymatic function, both of which are likely altered under changes in temperature (Jones et al., 1998), in particular, under extreme and relatively rapid temperature excursions for Symbiodinium (Lilley et al., 2010). For example, Claquin et al. (2008) demonstrated for six species of diatoms grown under a range of temperatures (between 5 and $35^{\circ} \mathrm{C}$ ), that $E / E_{k}$ is driven to $>1$ for temperatures both above and below the optimum for growth, i.e., inherent acclimation processes under non-optimal conditions cannot balance lightharvesting and downstream photosynthetic reactions. Given that the optimal temperature range for enzymes involved in photosynthesis and growth in corals of the present study are unknown, the deconvolution of temperature and light as factors in $E_{k}$ regulation is presently not possible. Ultimately this will be important as a loss of linear electron transport chain, but maintenance of absorption, inevitably places more pressure on the photosystem and the ability of Symbiodinium cells to buffer transient stressors.

Light utilization strategies were markedly different between seasons, and in spring three distinct patterns were observed: a "normal quenching profile" (equal utilization of $[1-C]$ and $[1-Q])$, preferential dynamic non-photochemical quenching, and preferential photochemical quenching (sensu Suggett et al., 2015). Such variability of inherent photosynthetic "strategy" is entirely consistent with the idea of Symbiodinium "ecotypes" (Iglesias-Prieto and Trench, 1997) or species optimized to different regimes, but able to co-exist within a single habitat through acclimation plasticity, i.e., the shallow reef flat of Heron Reef. Interestingly, light utilization strategies of Symbiodinium under spring conditions partially corresponded to phylogenetic groups (both host and symbiont, Table 1) that may reflect the light field of specific corals (Wangpraseurt et al., 2012). For example, coral species with symbionts utilizing preferential non-photochemical quenching were closely related (all in 
the family Acroporidae) and are known to harbor hostgeneralist Symbiodinium types (i.e., Symbiodinium ITS2 type $\mathrm{C} 3$, Table 1) that are typically acquired horizontally from a pool of free-living Symbiodinium (Nitschke et al., 2016). This supports the concept that host-specific differences in physical architectures (both skeletal and tissue structure) produce unique optical environments (Terán et al., 2010; Enríquez et al., 2017; Wangpraseurt et al., 2017a) that may force the photobiology of Symbiodinium to converge on host-specific strategies of light-utilization. Furthermore, a high capacity (or rapid induction) of non-photochemical quenching allows photosynthetic microorganisms (i.e., diatoms) to thrive in environments that have a high rate of change in light regimes (Lavaud et al., 2007), which for Symbiodinium that enter hosts horizontally, spans both free-living niches (e.g., sediment Nitschke et al., 2015) as well as symbiosis.

While it is tempting to interpret this photobiological trait and patterns of contrasting life history modes (i.e., symbiotic vs. free-living) and coral species-specific light fields (Enríquez et al., 2017) as reflecting trade-offs to a range of light regimes (Suggett et al., 2015), such a hypothesis requires extensive testing to fully establish whether such a pattern holds across a greater range of Symbiodinium genotypes and hosts. However, this notion is further supported by the observation that coral species with preferential photochemical quenching in this study harbor symbionts that are acquired vertically (i.e., maternal transmission), and include a number of ITS2 types which (at present) are not culturable (Krueger and Gates, 2012); e.g., P. lutea, P. cylindrical, and $M$. digitata all host Symbiodinium C15 (ITS2) at Heron Reef (Table 1), suggesting that Symbiodinium restricted to a specific light environment (i.e., host tissues) may have become optimized in regards to a single strategy of light-utilization. It must be noted, however, that the host-tissues themselves may interact with the fluorescence signals of the Symbiodinium cells and that the complex multi-cellular arrangement, varied pigment content, and mobile nature of the tissue add a level of uncertainty to inter-species comparisons. For example, Lichtenberg et al. (2016) retrieved fluorescence signatures inside coral tissues with a fiberoptic micro-probe and demonstrated that deeper tissue layers achieve different states of acclimation. However, this microscale technique was sensitive to tissue contraction and thus any correction factors that account for tissue depth require continuous knowledge of the physical (i.e., contracted or relaxed) state of the tissue. Ultimately, multiple attenuation coefficients that correspond to the coral tissue directly underneath the instrument fiber-optic are required; one each for the measuring light, the actinic light, and the fluorescence signals (e.g., Serôdio, 2004). Until a method is developed for the simultaneous measuring of these during the application of a light response curve, PSII fluorescence measurements deconvoluted for tissue depth and/or holobiont pigments will remain elusive in coral optics.

Low-light acclimation was observed in summer via upregulation of preferential utilization of $[1-C]$ at $E / E_{k}=1$, over non-photochemical quenching. Enhanced photochemical quenching, i.e., the closure of PSII reaction centers under exposure to high-light, is a response that is observed in Symbiodinium grown under or adapted to low-light conditions (Robison and Warner, 2006; Ragni et al., 2010) and/or exposure to elevated temperatures (Warner et al., 1996), potentially reflecting a reduction in the capacity of photosynthesis (Ragni et al., 2010). Given the range of quenching strategies adopted across all species in spring, it is perhaps surprising that a ubiquitous response was observed for the utilization of light under low-light conditions. However, this observation is consistent with the paradigm demonstrated in Hennige et al. (2008) (also Suggett et al., 2012) where Symbiodinium, independent of host species and depth, inherently optimize to maintain comparable utilization of $[1-C]$. Such a pattern is achieved through modulating the excitation energy that is dissipated via non-photochemical quenching pathways across the range of light environments (i.e., deep vs. shallow corals). In our study, optimisation of $[1-C]$ at the minimum saturating irradiance to similar levels across all species was consistent with this mechanism, i.e., the downregulation of $[1-Q]$ utilization, rather than major shifts in $[1-C]$. That our study does not adhere to this paradigm in spring may indicate that such patterns of $[1-C]$ optimisation become complex or non-linear under extremes (Suggett et al., 2012), such as the Heron reef flat habitat we examined here, and thus high-light environments may demand specific photoprotective requirements that exceed any capacity to buffer constant rates of photochemistry. An alternative explanation for the apparent downregulation of $[1-Q]$ utilization in summer may be related to limited time for induction of heat-dissipation mechanisms under RLC protocols. Whilst $20 \mathrm{~s}$ actinic light steps characterized species-specific differences in [1 - Q] utilization in spring, there is the potential that patterns are masked in summer by a seasonal change in the induction rate of $[1-Q]$ and that species-specific differences may only be evident beyond the transition from light-limited to light-saturated states of PSII (i.e., at $E / E_{k}>1$ ). As such, the time-dependent dynamics for non-photochemical quenching induction clearly warrant more targeted investigation in the future, particularly in the context of resolving photochemical dynamics of RLCs of differing light step durations.

The thermal tolerances or sensitivities are known for many species at Heron Reef and have been quantified at different times of year (Table 1), i.e., November (Hill et al., 2012), and February through March (Fitt et al., 2009; Fisher et al., 2012; Hillyer et al., 2017), utilizing similar experimental thresholds of ca. $32^{\circ} \mathrm{C}$. Whilst experimental studies of thermal-tolerance are typically limited to few species, our approach allows us to broadly characterize the relative hierarchy of tolerance under transient heat stress (strictly in relation to PSII photochemical efficiency), sensu Fisher et al. (2012), from high to low-sensitivity as follows; S. pistillata (being the only species to suffer total mortality) $<I$. palifera $=A$. formosa $=P$. damicornis $<A$. aspera $=A$. digitifera $<$ A. millepora $=$ P. cylindrica $<$ P. lutea $=M$. digitata .

A broad range of thermal ramping profiles utilized across other previous studies unfortunately limits inter-experiment comparability (Middlebrook et al., 2010). Furthermore, while we utilized identical heating rates and upper thermal limits across 
seasons, seasonal differences in the ambient temperatures (and also differences in light utilization strategies) could account for the minor alterations in the kinetics of PSII degradation (i.e., earlier, more gradual decline) between seasons. For example, under relatively acute thermal stress $\left(0.5^{\circ} \mathrm{C}\right.$ increases per hour to $31^{\circ} \mathrm{C}$ ), the kinetics of PSII function in A. millepora has previously been characterized as more sensitive compared to $P$. damicornis in spring (Hill et al., 2012), which is in contrast to our findings for these two species for this time of year. However, our data suggest that such inter-species comparisons of thermal tolerance must be interpreted cautiously and within a limited temporal context as $P$. damicornis changes significantly in thermal sensitivity following the height of summer. Overall our data are broadly consistent with corals exposed to similar thermal profiles. For example, the $\% F_{v} / F_{m}$ of $A$. aspera (in March) exposed to an equivalent heat stress $\left(1{ }^{\circ} \mathrm{C} \mathrm{d}^{-1}\right.$ to $\left.32^{\circ} \mathrm{C}\right)$ decreased to $70 \%$ relative to ambient controls (Hillyer et al., 2017). M. digitata (and to a lesser extent $P$. cylindrica) generally maintained PSII photochemical efficiency with little decline in $\% F_{v} / F_{m}$ in both seasons, consistent with the findings of Fisher et al. (2012) under a heat stress between 31 and $34^{\circ} \mathrm{C}$. P. lutea has previously been characterized as having a more "intermediate" thermal tolerance, i.e., equivalent to A. millepora (Fisher et al., 2012). Whilst control $P$. lutea demonstrated strong daily fluctuations in $\% F_{v} / F_{m}$ yields (potentially suggesting a significant night-time reduction of the plastoquinone pool; Hill and Ralph, 2005), $\% F_{v} / F_{m}$ in heat treated fragments did not change significantly and thus $P$. lutea is regarded as relatively thermally tolerant within this study. Our data thus contribute to the established hierarchy of thermal tolerance/sensitivity of corals and, whilst it should be noted that abiotic factors that vary on reefs but were not tested here (e.g., water movement) could alter susceptibility, our observations are consistent with expectations for Heron Reef with $P$. damicornis and S. pistillata the most likely to be susceptible to transient thermal stress.

Approximately $50 \%$ of the variance of PSII heat stress susceptibility was explained by a linear relationship with non-stressed $[1-C]$ (and $[1-Q]$ ) utilization $\left(\right.$ at $E / E_{k}=$ 1) in spring. Thus, corals that preferentially down-regulated photochemistry (i.e., the closure of PSII reaction centers) at and above the saturation point of PSII were also more resistant to subsequent heat stress. While this relationship is intriguing, utilization of photochemical quenching at any single point in time cannot serve as a diagnostic of thermal tolerance, especially as all species subsequently acclimated to utilize preferential photochemical quenching in summer (and the linear function was no longer apparent). Additionally, thermally induced changes in photochemical downregulation have been observed in both heat-sensitive and heat-tolerant Symbiodinium strains in culture (Robison and Warner, 2006) and in hospite (Warner et al., 1996). Thus, there is high potential for the environmental conditions in summer (decreasing-light, increasing temperature) to synergistically drive strong speciesindependent down-regulation of photochemistry and mask any potential light utilization diagnostic of heat-stress tolerance. That said, it is worth noting that our seasonal approach reveals that the strategy for dealing with light energy was unchanged for thermally tolerant species, i.e., thermally tolerant corals successfully balanced their innate ratio of $[1-Q]$ to $[1-C]$, despite significant seasonal changes in $E_{k}$, and thermally sensitive species exhibited seasonal swapping of light utilization strategies (especially in the heat sensitive A. formosa).

Ability of Symbiodinium to maintain light-utilization strategies across a range of environmental conditions has been discussed already (Hennige et al., 2008; Suggett et al., 2012); however, our data indicate that variability in lightutilization through time (at the scale of weeks to months) may be empirically related to differences in heat stress susceptibility. Such a framework is ripe for further experimentation, as temporal (long-term) stability or variability of photosystem function should be evident at the level of functional gene transcription (Scheibe et al., 2005), and thermally tolerant species may be "front-loaded" (sensu Barshis et al., 2013) with proteins that enable maintenance of physiological homeostasis that track or anticipate environmental change. Such a hypothesis requires extensive testing across a diverse range of coral-Symbiodinium symbioses, especially as exceptions are likely where anomalous temperatures target physiological pathways inherent to the coral host (Baird et al., 2009) or associated microbes (Diaz et al., 2016), that consequently cause Symbiodinium degradation. Indeed, the coral S. pistillata in our study is an exception to the linear relationship between $[1-C]$ utilization and thermal tolerance in spring, and despite utilizing preferential $[1-C]$ at similar levels to $M$. digitata and $P$. lutea, photochemical efficiency collapsed entirely for this species in response to transient heat stress. In other regions such as the Red Sea, S. pistillata exhibits robust host-specific responses to temperature stress and are considered thermally tolerant (Maor-Landaw et al., 2014; Maor-Landaw and Levy, 2016). However, the overall sensitive nature of the S. pistillataSymbiodinium symbioses at Heron Reef is well-documented (Table 1) and the host seems to be inherently less prepared to cope with transient heat stress than other species in this study (comparatively low mucus production, antioxidant enzyme function, and heat-shock protein content; Fitt et al., 2009).

Our novel study examining the photobiology of diverse coral Symbiodinium symbioses within a single environment allowed us to demonstrate the extent of symbiont photoacclimation that operates in response to changing light and temperature between seasons. Further characterisation of fundamental adaptive traits that underlie species-specific differences in commonly measured photobiological descriptors (such as the ratio of $[1-Q]$ to $[1-C]$ ) will undoubtedly prove crucial in defining the nicherange of Symbiodinium (Suggett et al., 2015). As Symbiodinium play a core role in the resilience of corals under environmental stress (especially during elevated temperatures), determining the utility and plasticity of such traits will enhance efforts to predict "winner and loser" coral-Symbiodinium symbioses under future climates (Loya et al., 2001; Fabricius et al., 2011). As widespread mass-bleaching events are predicted to become even more frequent under global climate change (Ainsworth et al., 2016), higher-throughput technologies in the area of coral-optics are required if photosynthesis-related traits are to be 
effectively utilized in the anticipative management of coral reef ecosystems.

\section{AUTHOR CONTRIBUTIONS}

MN and DS: Planned the study; MN, SGG, SG, and LF: Ran the experiments and performed fluorescence measurements. All authors interpreted the data, and MN and DS led the writing of the manuscript. All authors contributed to the final edited version of the manuscript.

\section{FUNDING}

This study was supported by ARC Discovery Grant DP160100271 to $\mathrm{DS}$.

\section{REFERENCES}

Ainsworth, T. D., Heron, S. F., Ortiz, J. C., Mumby, P. J., Grech, A., Ogawa, D., et al. (2016). Climate change disables coral bleaching protection on the Great Barrier Reef. Science 352, 338-342. doi: 10.1126/science.aac7125

Anthony, K., Connolly, S. R., and Hoegh-Guldberg, O. (2007). Bleaching, energetics, and coral mortality risk: effects of temperature, light, and sediment regime. Limnol. Oceanogr. 52, 716-726. doi: 10.4319/lo.2007.52.2.0716

Anthony, K., and Hoegh-Guldberg, O. (2003). Variation in coral photosynthesis, respiration and growth characteristics in contrasting light microhabitats: an analogue to plants in forest gaps and understoreys? Funct. Ecol. 17, 246-259. doi: 10.1046/j.1365-2435.2003.00731.x

Anthony, K., Ridd, P. V., Orpin, A. R., Larcombe, P., and Lough, J. (2004). Temporal variation of light availability in coastal benthic habitats: effects of clouds, turbidity, and tides. Limnol. Oceanogr. 49, 2201-2211. doi: 10.4319/lo.2004.49.6.2201

Bainbridge, S., Steinberg, C., and Furnas, M. (2010). "GBROOS-an ocean observing system for the Great Barrier Reef," in International Coral Reef Symposium (Ft. Lauderdale, FL), 529-533.

Baird, A. H., Bhagooli, R., Ralph, P. J., and Takahashi, S. (2009). Coral bleaching: the role of the host. Trends Ecol. Evol. 24, 16-20. doi: 10.1016/j.tree.2008.09.005

Baker, A. C., Glynn, P. W., and Riegl, B. (2008). Climate change and coral reef bleaching: an ecological assessment of long-term impacts, recovery trends and future outlook. Estuar. Coast. Shelf Sci. 80, 435-471. doi: 10.1016/j.ecss.2008.09.003

Barshis, D. J., Ladner, J. T., Oliver, T. A., Seneca, F. O., Traylor-Knowles, N., and Palumbi, S. R. (2013). Genomic basis for coral resilience to climate change. Proc. Natl. Acad. Sci. U.S.A. 110, 1387-1392. doi: 10.1073/pnas.1210224110

Brodersen, K. E., Lichtenberg, M., Ralph, P. J., Kühl, M., and Wangpraseurt, D. (2014). Radiative energy budget reveals high photosynthetic efficiency in symbiont-bearing corals. J. R. Soc. Interface 11:20130997. doi: 10.1098/rsif.2013.0997

Brown, B. E., Dunne, R. P., Goodson, M., and Douglas, A. (2000). Marine ecology: bleaching patterns in reef corals. Nature 404, 142-143. doi: 10.1038/35004657

Claquin, P., Probert, I., Lefebvre, S., and Veron, B. (2008). Effects of temperature on photosynthetic parameters and TEP production in eight species of marine microalgae. Aquat. Microb. Ecol. 51, 1-11. doi: 10.3354/ame01187

Cohen, I., and Dubinsky, Z. (2015). Long term photoacclimation responses of the coral Stylophora pistillata to reciprocal deep to shallow transplantation: photosynthesis and calcification. Front. Mar. Sci. 2:45. doi: 10.3389/fmars.2015.00045

Cooper, T. F., Ulstrup, K. E., Dandan, S. S., Heyward, A. J., Kühl, M., Muirhead, A., et al. (2011). Niche specialization of reef-building corals in the mesophotic zone: metabolic trade-offs between divergent Symbiodinium types. Proc. R. Soc. Lond. B Biol. Sci. 278, 1840-1850. doi: 10.1098/rspb.2010.2321

Diaz, J., Hansel, C., Apprill, A., Brighi, C., Zhang, T., Weber, L., et al. (2016). Species-specific control of external superoxide levels by the coral

\section{ACKNOWLEDGMENTS}

Coral collections were performed under the conditions of the Great Barrier Reef Marine Park Authority permits, numbered G15/37922.1 and G15/37538.1 held by MN and DS, respectively. We thank João Serôdio for valuable insight relating to the interpretation of the data. We also thank the staff of Heron Island Research Station for their assistance in the field.

\section{SUPPLEMENTARY MATERIAL}

The Supplementary Material for this article can be found online at: https://www.frontiersin.org/articles/10.3389/fmars. 2018.00045/full\#supplementary-material

holobiont during a natural bleaching event. Nat. Commun. 7:13801. doi: 10.1038/ncomms13801

Enríquez, S., and Borowitzka, M. A. (2010). "The use of the fluorescence signal in studies of seagrasses and macroalgae," in Chlorophyll a Fluorescence in Aquatic Sciences: Methods and Applications, eds D. J. Suggett, O. Prášil, and M. A. Borowitzka (Cham: Springer), 187-208.

Enríquez, S., Méndez, E. R., Hoegh-Guldberg, O., and Iglesias-Prieto, R. (2017). Key functional role of the optical properties of coral skeletons in coral ecology and evolution. Proc. R. Soc. Lon. B Biol. Sci. 284:20161667. doi: 10.1098/rspb.2016.1667

Enríquez, S., Méndez, E. R., and Prieto, R. I. (2005). Multiple scattering on coral skeletons enhances light absorption by symbiotic algae. Limnol. Oceanogr. 50, 1025-1032. doi: 10.4319/lo.2005.50.4.1025

Fabricius, K. E., Langdon, C., Uthicke, S., Humphrey, C., Noonan, S., De'ath, G., et al. (2011). Losers and winners in coral reefs acclimatized to elevated carbon dioxide concentrations. Nat. Clim. Chang. 1, 165-169. doi: $10.1038 /$ nclimate 1122

Fisher, P. L., Malme, M. K., and Dove, S. (2012). The effect of temperature stress on coral-Symbiodinium associations containing distinct symbiont types. Coral Reefs 31, 473-485. doi: 10.1007/s00338-011-0853-0

Fitt, W., Gates, R., Hoegh-Guldberg, O., Bythell, J., Jatkar, A., Grottoli, A., et al. (2009). Response of two species of Indo-Pacific corals, Porites cylindrica and Stylophora pistillata, to short-term thermal stress: the host does matter in determining the tolerance of corals to bleaching. J. Exp. Mar. Biol. Ecol. 373, 102-110. doi: 10.1016/j.jembe.2009.03.011

Frade, P., Bongaerts, P., Winkelhagen, A., Tonk, L., and Bak, R. (2008). In situ photobiology of corals over large depth ranges: a multivariate analysis on the roles of environment, host, and algal symbiont. Limnol. Oceanogr. 53, 2711-2723. doi: 10.4319/lo.2008.53.6.2711

Gorbunov, M. Y., Kolber, Z. S., Lesser, M. P., and Falkowski, P. G. (2001). Photosynthesis and photoprotection in symbiotic corals. Limnol. Oceanogr. 46, 75-85. doi: 10.4319/lo.2001.46.1.0075

Goyen, S., Pernice, M., Szabó, M., Warner, M. E., Ralph, P. J., and Suggett, D. J. (2017). A molecular physiology basis for functional diversity of hydrogen peroxide production amongst Symbiodinium spp.(Dinophyceae). Mar. Biol. 164:46. doi: 10.1007/s00227-017-3073-5

Hawkins, T. D., Krueger, T., Wilkinson, S. P., Fisher, P. L., and Davy, S. K. (2015). Antioxidant responses to heat and light stress differ with habitat in a common reef coral. Coral Reefs 34, 1229-1241. doi: 10.1007/s00338-0151345-4

Hennige, S. J., Smith, D. J., Perkins, R., Consalvey, M., Paterson, D. M., and Suggett, D. J. (2008). Photoacclimation, growth and distribution of massive coral species in clear and turbid waters. Mar. Ecol. Prog. Ser. 369, 77-88. doi: 10.3354/meps07612

Hennige, S. J., Suggett, D. J., Warner, M. E., McDougall, K. E., and Smith, D. J. (2009). Photobiology of Symbiodinium revisited: bio-physical and bio-optical signatures. Coral Reefs 28, 179-195. doi: 10.1007/s00338-008-0444-x 
Hill, R., Brown, C. M., DeZeeuw, K., Campbell, D. A., and Ralph, P. J. (2011). Increased rate of D1 repair in coral symbionts during bleaching is insufficient to counter accelerated photo-inactivation. Limnol. Oceanogr. 56, 139-146. doi: 10.4319/lo.2011.56.1.0139

Hill, R., Larkum, A., Prášil, O., Kramer, D., Szabó, M., Kumar, V., et al. (2012). Light-induced dissociation of antenna complexes in the symbionts of scleractinian corals correlates with sensitivity to coral bleaching. Coral Reefs 31, 963-975. doi: 10.1007/s00338-012-0914-Z

Hill, R., Larkum, A. W., Frankart, C., Kühl, M., and Ralph, P. J. (2004). Loss of functional Photosystem II reaction centres in zooxanthellae of corals exposed to bleaching conditions: using fluorescence rise kinetics. Photosyn. Res. 82, 59-72. doi: 10.1023/B:PRES.0000040444.41179.09

Hill, R., and Ralph, P. J. (2005). Diel and seasonal changes in fluorescence rise kinetics of three scleractinian corals. Funct. Plant Biol. 32, 549-559. doi: 10.1071/FP05017

Hillyer, K. E., Dias, D. A., Lutz, A., Wilkinson, S. P., Roessner, U., and Davy, S. K. (2017). Metabolite profiling of symbiont and host during thermal stress and bleaching in the coral Acropora aspera. Coral Reefs 219(Pt 4), 1-14. doi: 10.1007/s00338-016-1508-y

Hughes, T. P., Kerry, J. T., Álvarez-Noriega, M., Álvarez-Romero, J. G., Anderson, K. D., Baird, A. H., et al. (2017). Global warming and recurrent mass bleaching of corals. Nature 543, 373-377. doi: 10.1038/nature21707

Iglesias-Prieto, R., Beltrán, V., LaJeunesse, T., Reyes-Bonilla, H., and Thomé, P. (2004). Different algal symbionts explain the vertical distribution of dominant reef corals in the eastern Pacific. Proc. R. Soc. Lond. Ser. B Biol. Sci. 271, 1757-1763. doi: 10.1098/rspb.2004.2757

Iglesias-Prieto, R., and Trench, R. (1997). Acclimation and adaptation to irradiance in symbiotic dinoflagellates. II. Response of chlorophyll-protein complexes to different photon-flux densities. Mar. Biol. 130, 23-33. doi: $10.1007 / \mathrm{s} 002270050221$

Jeans, J., Campbell, D. A., and Hoogenboom, M. O. (2013). Increased reliance upon photosystem II repair following acclimation to highlight by coral-dinoflagellate symbioses. Photosyn. Res. 118, 219-229. doi: 10.1007/s11120-013-9918-y

Jones, R., Hoegh-Guldberg, O., Larkum, A., and Schreiber, U. (1998). Temperature-induced bleaching of corals begins with impairment of the $\mathrm{CO}_{2}$ fixation mechanism in zooxanthellae. Plant Cell Environ. 21, 1219-1230. doi: 10.1046/j.1365-3040.1998.00345.x

Kline, D. I., Teneva, L., Hauri, C., Schneider, K., Miard, T., Chai, A., et al. (2015). Six month in situ high-resolution carbonate chemistry and temperature study on a coral reef flat reveals asynchronous $\mathrm{pH}$ and temperature anomalies. PLoS ONE 10:e0127648. doi: 10.1371/journal.pone.0127648

Krueger, T., and Gates, R. D. (2012). Cultivating endosymbionts - host environmental mimics support the survival of Symbiodinium C15 ex hospite. J. Exp. Mar. Biol. Ecol. 413, 169-176. doi: 10.1016/j.jembe.2011.12.002

Krueger, T., Hawkins, T. D., Becker, S., Pontasch, S., Dove, S., Hoegh-Guldberg, O., et al. (2015). Differential coral bleaching-Contrasting the activity and response of enzymatic antioxidants in symbiotic partners under thermal stress. Comp. Biochem. Physiol. Part A Mol. Integr. Physiol. 190, 15-25. doi: 10.1016/j.cbpa.2015.08.012

LaJeunesse, T. C., Loh, W. K. W., van Woesik, R., Hoegh-Guldberg, O., Schmidt, G. W., and Fitt, W. K. (2003). Low symbiont diversity in southern Great Barrier Reef corals, relative to those of the Caribbean. Limnol. Oceanogr. 48, 2046-2054. doi: 10.4319/lo.2003.48.5.2046

Lavaud, J., Strzepek, R. F., and Kroth, P. G. (2007). Photoprotection capacity differs among diatoms: possible consequences on the spatial distribution of diatoms related to fluctuations in the underwater light climate. Limnol. Oceanogr. 52, 1188-1194. doi: 10.4319/lo.2007.52.3.1188

Lesser, M. P., and Farrell, J. H. (2004). Exposure to solar radiation increases damage to both host tissues and algal symbionts of corals during thermal stress. Coral Reefs 23, 367-377. doi: 10.1007/s00338-004-0392-z

Lesser, M. P., Slattery, M., Stat, M., Ojimi, M., Gates, R. D., and Grottoli, A. (2010). Photoacclimatization by the coral Montastraea cavernosa in the mesophotic zone: light, food, and genetics. Ecology 91, 990-1003. doi: 10.1890/090313.1

Levy, O., Dubinsky, Z., and Achituv, Y. (2003). Photobehavior of stony corals: responses to light spectra and intensity. J. Exp. Biol. 206, 4041-4049. doi: $10.1242 /$ jeb.00622
Lichtenberg, M., Larkum, A. W., and Kühl, M. (2016). Photosynthetic acclimation of Symbiodinium in hospite depends on vertical position in the tissue of the scleractinian coral Montastrea curta. Front. Microbiol. 7:230. doi: $10.3389 /$ fmicb. 2016.00230

Lilley, R., Ralph, P. J., and Larkum, A. W. (2010). The determination of activity of the enzyme Rubisco in cell extracts of the dinoflagellate alga Symbiodinium sp. by manganese chemiluminescence and its response to short-term thermal stress of the alga. Plant Cell Environ. 33, 995-1004. doi: 10.1111/j.1365-3040.2010.02121.x

Louis, Y. D., Kaullysing, D., Gopeechund, A., Mattan-Moorgawa, S., Bahorun, T., Dyall, S. D., et al. (2016). In hospite Symbiodinium photophysiology and antioxidant responses in Acropora muricata on a coast-reef scale: implications for variable bleaching patterns. Symbiosis 68, 61-72. doi: 10.1007/s13199-016-0380-4

Loya, Y., Sakai, K., Yamazato, K., Nakano, Y., Sambali, H., and van Woesik, R. (2001). Coral bleaching: the winners and the losers. Ecol. Lett. 4, 122-131. doi: 10.1046/j.1461-0248.2001.00203.x

Madin, J. S., Anderson, K. D., Andreasen, M. H., Bridge, T. C., Cairns, S. D., Connolly, S. R., et al. (2016). The Coral Trait Database, a curated database of trait information for coral species from the global oceans. Sci. Data 3:160017. doi: $10.1038 /$ sdata.2016.17

Maor-Landaw, K., Karako-Lampert, S., Ben-Asher, H. W., Goffredo, S., Falini, G., Dubinsky, Z., et al. (2014). Gene expression profiles during short-term heat stress in the red sea coral Stylophora pistillata. Glob. Chang. Biol. 20, 3026-3035. doi: $10.1111 /$ gcb.12592

Maor-Landaw, K., and Levy, O. (2016). Gene expression profiles during shortterm heat stress; branching vs. massive Scleractinian corals of the Red Sea. PeerJ 4:e1814. doi: $10.7717 /$ peerj. 1814

McCabe Reynolds, J., Bruns, B. U., Fitt, W. K., and Schmidt, G. W. (2008). Enhanced photoprotection pathways in symbiotic dinoflagellates of shallowwater corals and other cnidarians. Proc. Natl. Acad. Sci. U.S.A. 105, 13674-13678. doi: 10.1073/pnas.0805187105

Michael, K. J., Veal, C. J., and Nunez, M. (2012). Attenuation coefficients of ultraviolet and photosynthetically active wavelengths in the waters of Heron Reef, Great Barrier Reef, Australia. Mar. Freshw. Res. 63, 142-149. doi: 10.1071/MF11106

Middlebrook, R., Anthony, K. R., Hoegh-Guldberg, O., and Dove, S. (2010). Heating rate and symbiont productivity are key factors determining thermal stress in the reef-building coral Acropora formosa. J. Exp. Biol. 213, 1026-1034. doi: $10.1242 /$ jeb.031633

Middlebrook, R., Hoegh-Guldberg, O., and Leggat, W. (2008). The effect of thermal history on the susceptibility of reef-building corals to thermal stress. J. Exp. Biol. 211, 1050-1056. doi: 10.1242/jeb.013284

Mumby, P. J., Chisholm, J. R., Edwards, A. J., Andrefouet, S., and Jaubert, J. (2001). Cloudy weather may have saved Society Island reef corals during the 1998 ENSO event. Mar. Ecol. Prog. Ser. 222, 209-216. doi: 10.3354/meps222209

Nitschke, M. R., Davy, S. K., Cribb, T. H., and Ward, S. (2015). The effect of elevated temperature and substrate on free-living Symbiodinium cultures. Coral Reefs 34, 1-11. doi: 10.1007/s00338-014-1220-8

Nitschke, M. R., Davy, S. K., and Ward, S. (2016). Horizontal transmission of Symbiodinium cells between adult and juvenile corals is aided by benthic sediment. Coral Reefs 35, 335-344. doi: 10.1007/s00338-015-1349-0

Oakley, C. A., Schmidt, G. W., and Hopkinson, B. M. (2014). Thermal responses of Symbiodinium photosynthetic carbon assimilation. Coral Reefs 33, 501-512. doi: $10.1007 / \mathrm{s} 00338-014-1130-9$

Oliver, T., and Palumbi, S. (2011). Do fluctuating temperature environments elevate coral thermal tolerance? Coral Reefs 30, 429-440. doi: 10.1007/s00338-011-0721-y

Oxborough, K., Moore, C. M., Suggett, D. J., Lawson, T., Chan, H. G., and Geider, R. J. (2012). Direct estimation of functional PSII reaction center concentration and PSII electron flux on a volume basis: a new approach to the analysis of Fast Repetition Rate fluorometry (FRRf) data. Limnol. Oceanogr. Methods 10, 142-154. doi: 10.4319/lom.2012.10.142

Perkins, R. G., Kromkamp, J. C., Serôdio, J., Lavaud, J., Jesus, B., Mouget, J.L., et al. (2010). "The application of variable chlorophyll fluorescence to microphytobenthic biofilms," in Chlorophyll a Fluorescence in Aquatic Sciences: Methods and Applications, eds D. J. Suggett, O. Prášil, and M. A. Borowitzka (Cham: Springer), 237-275. 
Ragni, M., Airs, R. L., Hennige, S. J., Suggett, D. J., Warner, M. E., and Geider, R. J. (2010). PSII photoinhibition and photorepair in Symbiodinium (Pyrrhophyta) differs between thermally tolerant and sensitive phylotypes. Mar. Ecol. Prog. Ser. 406, 57-70. doi: 10.3354/meps08571

Ralph, P. J., and Gademann, R. (2005). Rapid light curves: a powerful tool to assess photosynthetic activity. Aquat. Bot. 82, 222-237. doi: 10.1016/j.aquabot.2005.02.006

Roberty, S., Bailleul, B., Berne, N., Franck, F., and Cardol, P. (2014). PSI Mehler reaction is the main alternative photosynthetic electron pathway in Symbiodinium sp., symbiotic dinoflagellates of cnidarians. New Phytol. 204, 81-91. doi: 10.1111/nph.12903

Roberty, S., Fransolet, D., Cardol, P., Plumier, J.-C., and Franck, F. (2015). Imbalance between oxygen photoreduction and antioxidant capacities in Symbiodinium cells exposed to combined heat and high light stress. Coral Reefs 34, 1063-1073. doi: 10.1007/s00338-015-1328-5

Robison, J. D., and Warner, M. E. (2006). Differential impacts of photoacclimation and thermal stress on the photobiology of four different phylotypes of Symbiodinium (Pyrrhophyta). J. Phycol. 42, 568-579. doi: $10.1111 /$ j.1529-8817.2006.00232.x

Roth, M. S. (2014). The engine of the reef: photobiology of the coral-algal symbiosis. Front. Microbiol. 5:422. doi: 10.3389/fmicb.2014.00422

Roth, M. S., Latz, M. I., Goericke, R., and Deheyn, D. D. (2010). Green fluorescent protein regulation in the coral Acropora yongei during photoacclimation. J. Exp. Biol. 213, 3644-3655. doi: 10.1242/jeb.040881

Salih, A., Larkum, A., Cox, G., Kühl, M., and Hoegh-Guldberg, O. (2000). Fluorescent pigments in corals are photoprotective. Nature 408, 850-853. doi: $10.1038 / 35048564$

Sampayo, E. M., Franceschinis, L., Hoegh-Guldberg, O., and Dove, S. (2007). Niche partitioning of closely related symbiotic dinoflagellates. Mol. Ecol. 16, 3721-3733. doi: 10.1111/j.1365-294X.2007.03403.x

Sawall, Y., Al-Sofyani, A., Banguera-Hinestroza, E., and Voolstra, C. R. (2014). Spatio-temporal analyses of Symbiodinium physiology of the coral Pocillopora verrucosa along large-scale nutrient and temperature gradients in the Red Sea. PLoS ONE 9:e103179. doi: 10.1371/journal.pone. 0103179

Scheibe, R., Backhausen, J. E., Emmerlich, V., and Holtgrefe, S. (2005). Strategies to maintain redox homeostasis during photosynthesis under changing conditions. J. Exp. Bot. 56, 1481-1489. doi: 10.1093/jxb/eri181

Serôdio, J. (2004). Analysis of variable chlorophyll fluorescence in microphytobenthos assemblages: implications of the use of depth-integrated measurements. Aquat. Microb. Ecol. 36, 137-152. doi: 10.3354/ame036137

Serôdio, J., Vieira, S., Cruz, S., and Barroso, F. (2005). Short-term variability in the photosynthetic activity of microphytobenthos as detected by measuring rapid light curves using variable fluorescence. Mar. Biol. 146, 903-914. doi: 10.1007/s00227-004-1504-6

Serôdio, J., Vieira, S., Cruz, S., and Coelho, H. (2006). Rapid light-response curves of chlorophyll fluorescence in microalgae: relationship to steady-state light curves and non-photochemical quenching in benthic diatom-dominated assemblages. Photosyn. Res. 90, 29-43. doi: 10.1007/s11120-006-9105-5

Slavov, C., Schrameyer, V., Reus, M., Ralph, P. J., Hill, R., Büchel, C., et al. (2016). "Super-quenching" state protects Symbiodinium from thermal stressimplications for coral bleaching. Biochim. Biophys. Acta 1857, 840-847. doi: 10.1016/j.bbabio.2016.02.002

Smith, D. J., Suggett, D. J., and Baker, N. R. (2005). Is photoinhibition of zooxanthellae photosynthesis the primary cause of thermal bleaching in corals? Glob. Chang. Biol. 11, 1-11. doi: 10.1111/j.1529-8817.2003.00895.x

Stat, M., Loh, W. K. W., Hoegh-Guldberg, O., and Carter, D. A. (2008). Symbiont acquisition strategy drives host-symbiont associations in the southern Great Barrier Reef. Coral Reefs 27, 763-772. doi: 10.1007/s00338-008$0412-5$

Suggett, D. J., Goyen, S., Evenhuis, C., Szabó, M., Pettay, D. T., Warner, M. E., et al. (2015). Functional diversity of photobiological traits within the genus Symbiodinium appears to be governed by the interaction of cell size with cladal designation. New Phytol. 208, 370-381. doi: 10.1111/nph. 13483

Suggett, D. J., Kikuchi, R. K., Oliveira, M. D., Spanó, S., Carvalho, R., and Smith, D. J. (2012). Photobiology of corals from Brazil's near-shore marginal reefs of Abrolhos. Mar. Biol. 159, 1461-1473. doi: 10.1007/s00227-012-1925-6
Suggett, D. J., and Smith, D. J. (2011). Interpreting the sign of coral bleaching as friend vs. foe. Glob. Change Biol. 17, 45-55. doi: 10.1111/j.1365-2486.2009.02155.x

Takahashi, S., Nakamura, T., Sakamizu, M., van Woesik, R., and Yamasaki, H. (2004). Repair machinery of symbiotic photosynthesis as the primary target of heat stress for reef-building corals. Plant Cell Physiol. 45, 251-255. doi: $10.1093 / \mathrm{pcp} / \mathrm{pch} 028$

Takahashi, S., Whitney, S., Itoh, S., Maruyama, T., and Badger, M. (2008). Heat stress causes inhibition of the de novo synthesis of antenna proteins and photobleaching in cultured Symbiodinium. Proc. Natl. Acad. Sci. U.S.A. 105, 4203-4208. doi: 10.1073/pnas.0708554105

Tchernov, D., Gorbunov, M. Y., de Vargas, C., Yadav, S. N., Milligan, A. J., Häggblom, M., et al. (2004). Membrane lipids of symbiotic algae are diagnostic of sensitivity to thermal bleaching in corals. Proc. Natl. Acad. Sci. U.S.A. 101, 13531-13535. doi: 10.1073/pnas.0402907101

Terán, E., Méndez, E. R., Enríquez, S., and Iglesias-Prieto, R. (2010). Multiple light scattering and absorption in reef-building corals. Appl. Opt. 49, 5032-5042. doi: 10.1364/AO.49.005032

Titlyanov, E., Titlyanova, T., Yamazato, K., and Van Woesik, R. (2001). Photoacclimation dynamics of the coral Stylophora pistillata to low and extremely low light. J. Exp. Mar. Biol. Ecol. 263, 211-225. doi: 10.1016/S0022-0981(01)0 0309-4

Ulstrup, K. E., Hill, R., Van Oppen, M., Larkum, A., and Ralph, P. (2008). Seasonal variation in the photo-physiology of homogeneous and heterogeneous Symbiodinium consortia in two scleractinian corals. Mar. Ecol. Prog. Ser. 361, 139-150. doi: $10.3354 /$ meps 07360

Vieira, S., Calado, R., Coelho, H., and Serôdio, J. (2009). Effects of light exposure on the retention of kleptoplastic photosynthetic activity in the sacoglossan mollusc Elysia viridis. Mar. Biol. 156:1007. doi: 10.1007/s00227-009-1144-y

Wangpraseurt, D., Holm, J. B., Larkum, A. W., Pernice, M., Ralph, P. J., Suggett, D. J., et al. (2017a). In vivo microscale measurements of light and photosynthesis during coral bleaching: evidence for the optical feedback loop? Front. Microbiol. 8:59. doi: 10.3389/fmicb.2017.00059

Wangpraseurt, D., Larkum, A., Ralph, P., and Kühl, M. (2012). Light gradients and optical microniches in coral tissues. Front. Microbiol. 3:316. doi: $10.3389 /$ fmicb. 2012.00316

Wangpraseurt, D., Larkum, A. W., Franklin, J., Szabó, M., Ralph, P. J., and Kühl, M. (2014). Lateral light transfer ensures efficient resource distribution in symbiont-bearing corals. J. Exp. Biol. 217, 489-498. doi: 10.1242/jeb.091116

Wangpraseurt, D., Wentzel, C., Jacques, S. L., Wagner, M., and Kühl, M. (2017b). In vivo imaging of coral tissue and skeleton with optical coherence tomography. J. R. Soc. Interface 14:20161003. doi: 10.1098/rsif. 2016.1003

Warner, M., Chilcoat, G., McFarland, F., and Fitt, W. (2002). Seasonal fluctuations in the photosynthetic capacity of photosystem II in symbiotic dinoflagellates in the Caribbean reef-building coral Montastraea. Mar. Biol. 141, 31-38. doi: $10.1007 / \mathrm{s} 00227-002-0807-8$

Warner, M. E., Fitt, W. K., and Schmidt, G. W. (1999). Damage to photosystem II in symbiotic dinoflagellates: a determinant of coral bleaching. Proc. Natl. Acad. Sci. U.S.A. 96, 8007-8012. doi: 10.1073/pnas.96. 14.8007

Warner, M. E., Lesser, M. P., and Ralph, P. J. (2010). "Chlorophyll fluorescence in reef building corals," in Chlorophyll a Fluorescence in Aquatic Sciences: Methods and Applications, eds D. J. Suggett, O. Prášil, and M. A. Borowitzka (Cham: Springer), 209-222.

Warner, M. E., and Suggett, D. J. (2016). “The Photobiology of Symbiodinium spp.: linking physiological diversity to the implications of stress,"in The Cnidaria Past, Present and Future: The World of Medusa and Her Sisters, eds S. Goffredo and Z. Dubinsky (Cham: Springer), 489-509.

Warner, M., Fitt, W., and Schmidt, G. (1996). The effects of elevated temperature on the photosynthetic efficiency of zooxanthellae in hospite from four different species of reef coral: a novel approach. Plant Cell Environ. 19, 291-299. doi: 10.1111/j.1365-3040.1996.tb00251.x

Weis, V. M. (2008). Cellular mechanisms of cnidarian bleaching: stress causes the collapse of symbiosis. J. Exp. Biol. 211, 3059-3066. doi: 10.1242/jeb. 009597

Wiedenmann, J., D’Angelo, C., Smith, E. G., Hunt, A. N., Legiret, F.-E., Postle, A. D., et al. (2013). Nutrient enrichment can increase the susceptibility 
of reef corals to bleaching. Nat. Clim. Chang. 3, 160-164. doi: 10.1038/ nclimate 1661

Winters, G., Beer, S., Zvi, B. B., Brickner, I., and Loya, Y. (2009). Spatial and temporal photoacclimation of Stylophora pistillata: zooxanthella size, pigmentation, location and clade. Mar. Ecol. Prog. Ser. 384, 107-119. doi: $10.3354 /$ meps08036

Wooldridge, S. A., Heron, S. F., Brodie, J. E., Done, T. J., Masiri, I., and Hinrichs, S. (2017). Excess seawater nutrients, enlarged algal symbiont densities and bleaching sensitive reef locations: 2. A regional-scale predictive model for the Great Barrier Reef, Australia. Mar. Pollut. Bull. 114, 343-354. doi: 10.1016/j.marpolbul.2016.09.045
Conflict of Interest Statement: The authors declare that the research was conducted in the absence of any commercial or financial relationships that could be construed as a potential conflict of interest.

Copyright (c) 2018 Nitschke, Gardner, Goyen, Fujise, Camp, Ralph and Suggett. This is an open-access article distributed under the terms of the Creative Commons Attribution License (CC BY). The use, distribution or reproduction in other forums is permitted, provided the original author(s) and the copyright owner are credited and that the original publication in this journal is cited, in accordance with accepted academic practice. No use, distribution or reproduction is permitted which does not comply with these terms. 